\title{
Jostling for Advantage or Not: Choosing Between Patent Portfolio Races and Ex Ante Licensing.
}

\author{
Ralph Siebert (Purdue University) * \\ Georg von Graevenitz (University of Munich) ${ }^{\dagger}$
}

August 20, 2009

\begin{abstract}
Complex high technology industries are increasingly affected by patent thickets in which firms' patents mutually block the use of important technologies. Firms facing patent thickets patent intensively to acquire bargaining chips and use licensing to ensure freedom to operate. Such licensing allows rivals to either avoid or resolve hold-up from blocking patents. R\&D incentives depend on whether licensing takes place ex ante or ex post. We model the choice between ex ante licensing and entry into patent portfolio races leading to ex post licensing. It is shown that higher degrees of blocking lead firms to license ex post, while stronger product market competition leads firms to license ex ante. Empirical results support these theoretical predictions.
\end{abstract}

JEL: L13, L49, L63.

Keywords: Hold-Up Problem, Licensing, Innovation, Patent Race, Patent Thicket, Research Joint Ventures.

\footnotetext{
Acknowledgments: This paper is a complete revision of the original which was issued as CEPR DP 5373 and Transregio SFB Working Paper 184. We would like to thank Steffen Brenner, Walter Elberfeld, Bronwyn Hall, Dietmar Harhoff and his group at INNO-tec, Christa Hainz, Heidrun Hoppe, Jos Jansen, Klaus Schmidt and Konrad Stahl for discussions on this paper. Seminar audiences at Würzburg University, EARIE 2006 and at the $5^{t h}$ workshop of the SFB TR/15 provided additional comments. Georg von Graevenitz gratefully acknowledges the support of the ESRC through its Postdoctoral Fellowship scheme and its support for ELSE, as well as the support of the SFB Transregio 15 during the writing of this paper. The usual disclaimer applies.
}

${ }^{*}$ Ralph Siebert, Purdue University, Department of Economics, Krannert School of Management, 403 West State Street, West Lafayette, IN 47907-2056, rsiebert@purdue.edu.

${ }^{\dagger}$ Georg von Graevenitz, graevenitz@bwl.uni-muenchen.de, INNO-tec, Munich School of Management, Kaulbachstraße 45, D - 80539, Munich. 


\section{Introduction}

There has been a significant shift of patenting behavior in high technology sectors providing modular technologies such as semiconductors. Firms selling such technologies for whom patents were of little strategic importance before 1984 started to patent for strategic reasons after this date (Jaffe, 2000). ${ }^{1}$ The complexity and modularity of technology combined with strong increases in the number of patent applications has given rise to patent thickets (Shapiro, 2001; Hall and Ziedonis, 2001). A patent thicket consists of complementary patents related to one technology. The patents in a patent thicket belong to many rival firms. In the absence of cross licensing agreements, or patent pools, use of the technology is blocked.

Avoiding exposure to rivals' blocking patents is difficult because firms are often not aware of the precise technological trajectory pursued by their rivals (Grindley and Teece, 1997). Additionally, the complexity of high technology products gives rise to connections between patents that are not anticipated. Compounding these problems, the limits of patent rights are always open to interpretation which can lead to unanticipated overlap of patents. Finally, patent offices have limited resources and may overlook prior art or patent overlap (Lemley, 2001). ${ }^{2}$

In order to contain the threat of hold-up, firms build up large patent portfolios which provide "freedom to operate" (Grindley and Teece, 1997; Lichtenthaler, 2007; Davis, 2008). Firms with larger patent portfolios can threaten a rival with multiple counter-suits should that rival seek to hold them up. Once the logic of mutual hold-up takes root in an industry, firms enter patent portfolio races. Each firm seeks to build up a larger portfolio of patents than its rivals (Hall and Ziedonis, 2001; Ziedonis, 2004). Firms escape from mutual hold-up by cross licensing patent portfolios (Grindley and Teece, 1997; Lemley, 2001). The terms of cross licensing deals usually depend on which firm has most patents (Lemley, 2001; Somaya, 2003).

Where licensing takes place to ensure "freedom to operate", the aims of the licensing parties are somewhat different from settings previously analyzed in the literature on licensing (Scotchmer, 2005). ${ }^{3}$ The parties are not interested in technology transfer and do not coordinate

\footnotetext{
${ }^{1}$ This shift is documented particularly clearly for the semiconductor industry (Grindley and Teece, 1997; Hall and Ziedonis, 2001; Somaya, 2003; Ziedonis, 2004; Lichtenthaler, 2007; Davis, 2008). There is recent evidence that strategic patenting also affects other industries such as software or optics (Schankerman and Noel, 2006; von Graevenitz et al., 2008).

${ }^{2}$ Problems caused by strategic patenting, increases in patent litigation (Lanjouw and Schankerman, 2004) and the growing backlog of patents at the USPTO (Quillen et al., 2003) have led to an intensive policy debate on the current state of the patent system in the United States (Federal Trade Commission, 2003; American Intellectual Property Law Association, 2004).

${ }^{3}$ Lichtenthaler (2007) shows that this motivation for licensing is becoming prevalent in other key industries outside of semiconductors.
} 
their R\&D efforts (Grindley and Teece, 1997; Lichtenthaler, 2007). Typically, firms also have no intention of joint marketing or sales of products in which case they might set up a patent pool (Lerner and Tirole, 2004; Lerner et al., 2007). Rather the firms indemnify each other against patent litigation in a specific technological field and for a specific period of time. ${ }^{4}$

Previous work, which discusses licensing in patent thickets (Grindley and Teece, 1997; Shapiro, 2001; Clark and Konrad, 2005), emphasizes ex post licensing, which takes place once firms have acquired patents. However, licensing may also take place ex ante, at the start of a research program. Ex ante licensing may reduce the intensity of a patent portfolio race. Siebert and von Graevenitz (2008) find that the majority of licensing contracts, signed in the semiconductor industry between 1989-1999, were ex ante contracts. Ex ante contracts cover pre-specified technologies and contain all patents pertinent to these. The modularity of semiconductor technology and the efforts of the entire industry to map out future technological developments ${ }^{5}$ allow firms to specify what is covered by an ex ante license. ${ }^{6}$ This raises the question: when do firms use ex ante licensing to avoid patent portfolio races?

In this paper, we show that ex ante contracts which ensure ex post symmetry of rivals' patent portfolios can reduce the intensity of patent portfolio races. ${ }^{7}$ It is profitable to engage in such licensing contracts if firms anticipate that a patent portfolio race is more likely to be intense and costly. This is the case if the patent portfolio race results in a more asymmetric distribution of patents and if product market competition between rival firms is more intense.

The decision to license ex ante or ex post depends on two innovation incentives: the competitive threat and the profit incentive. These incentives are functions of the degree of blocking and the degree of product market substitution between firms' products. The incentives determine firms' equilibrium R\&D investments. Under ex post licensing investments will be excessively high from a private perspective if the competitive threat is strong. In this case, ex ante licensing will be more profitable than ex post licensing as there is no competitive threat under ex ante licensing. High degrees of blocking dampen the competitive threat, raising the probability that

\footnotetext{
${ }^{4}$ For instance, Texas Instruments signed cross licensing agreements with several significant Japanese semiconductor firms (Matsushita, NEC, Mitsubishi, Seiko Epson and Toko) for periods of five years in 1991. Some of these were extensions of previous licensing contracts.

${ }^{5}$ The International Technology Roadmap for Semiconductors (ITRS) is an assessment of the semiconductor industry's future technology requirements for a period of fifteen years. Firms use the roadmap to inform their research and development strategies.

${ }^{6}$ In Appendix A.4 we provide examples of descriptions of such contracts from our data. These show that firms can clarify which technologies are covered by forward looking agreements.

${ }^{7}$ Ex ante contracts that are contingent on the patenting success of firms induce ex post asymmetry. Such contingent ex ante contracts do not reduce the strong patenting incentives firms face - their effect would be rather similar to that of the ex post licensing contracts we model.
} 
ex post licensing is most profitable. A larger degree of product market competition increases the competitive threat, raising the probability that ex ante licensing is most profitable.

These predictions are tested empirically using annual data from the semiconductor industry between 1989-1999. This industry provides an ideal setting to test our model, as there is abundant evidence that patent thickets affect the semiconductor industry (Grindley and Teece, 1997; Hall and Ziedonis, 2001; Somaya, 2003; Ziedonis, 2004; Lichtenthaler, 2007; Davis, 2008). Controlling for varying levels of transaction costs, average firm size, firm size differences, industry revenues and patent stocks, we cannot reject our theoretical predictions. Our results clarify how licensing in patent thickets affects firms' patenting incentives.

Bessen and Maskin (2000) study differentiated products and differentiated research lines in order to model innovation in a complex technology. They focus on the incentive effects of patent protection. Blocking arises if the first innovator's patent is defined with sufficient leading breadth to prevent follow on inventors from obtaining a patent (Green and Scotchmer, 1995; Bessen and Maskin, 2000). In this setting, patent offices never err and patents do not overlap. However, existing empirical work on patenting suggests strongly that overlapping patent rights exist, especially in complex technologies (Lemley, 2001; Shapiro, 2003; Ziedonis, 2004). Often overlapping patents arise contemporaneously. Therefore, we analyze the effects that blocking patents have on firms' $\mathrm{R} \& \mathrm{D}$ and licensing decisions.

The remainder of the paper is structured as follows. In Section 2 we describe the model, while Section 3 contains theoretical results. Section 4 provides simulations of the model and Section 5 sets out an empirical test of the theoretical predictions. We conclude in Section 6 .

\section{The model}

In this section we provide a model of licensing in industries supplying products based on complex technologies. Such industries are affected by patent thickets. To resolve blocking in patent thickets firms can cross license patent portfolios. Licensing contracts can be written before (ex ante licensing) or after (ex post licensing) patenting of a technological opportunity has begun. Our model shows how the degree of blocking and the degree of substitutability or complementarity of firms' products affect the expected values of ex ante and ex post licensing. ${ }^{8}$ We derive conditions under which firms prefer ex ante to ex post licensing contracts. These

\footnotetext{
${ }^{8}$ To simplify our language we will refer mostly to the degree of substitutability of firms' products below. If not stated otherwise the statements we make apply to cases in which products are complements as well.
} 
conditions underpin hypotheses which we test empirically in Section 5.

In our model two firms compete in the product and technology markets. The technology they employ is complex. Firms' products may be substitutes or complements. Technological competition is for leadership on a set of new technologies too complex to be protected by only a few patents. We refer to such a set of technologies as a technological opportunity.

As the technology firms use is complex, patents acquired by leader and follower may overlap, resulting in blocked patents. These patents can be held up and will not be employed without a cross license insuring against this. The leader on a technological opportunity has more unblocked patents and acquires a greater share of the rents from the opportunity than the follower. Firms enter into patent portfolio races to determine who becomes the leader.

If blocking is complete the leader must cross license with the follower to obtain any benefit from her new patents. If blocking is low she can extract some economic rents using her patents even if there is no license. For simplicity we assume that all the follower's patents are blocked and the follower always needs to cross license. More generally, a leader is be less affected by blocking than a follower but as blocking becomes complete, the leader's advantage vanishes.

We model patent portfolio races as a game in which both firms simultaneously commit to the level of $R \& D$ investments. Then firms cannot adjust their research efforts during patent portfolio races. This assumption is supported by the fact that patent portfolio races take place over short time spans during which firms receive no signals of rivals' actions (Grindley and Teece, 1997).

Our model rests on two central assumptions. First, that the degree of blocking is exogenously determined. Second, the follower will hold only blocked patents. Both assumptions may be relaxed. We relax the second assumption simulating the model in Section 4 and show that our predictions are robust. Endogenizing blocking requires additional assumptions and is left to a separate paper (Siebert and von Graevenitz, 2008).

We analyze the following game:

Stage 1 Each firm simultaneously chooses whether or not to contract ex ante with the other.

Stage 2 Firms simultaneously and independently choose a hazard rate $h_{i}$ of becoming the leader.

Stage 3 If firms have not previously contracted, they bargain over the surplus embodied in the patents covering the technological opportunity and cross license ex post.

Note that both ex ante and ex post licensing lead to independent R\&D investments determining the hazard rate of becoming technology leader on the new technological opportunity. 
Firms do not coordinate their investments under ex ante licensing as there is no exchange of technological expertise - an ex ante licensing contract just prevents potential hold-up.

Using the concept of sub-game perfection we solve the game by backwards induction.

\subsection{General assumptions}

To model the effects of blocking on firms' profits we introduce the notion of the quality of firms' patent portfolios. Initially both firms have patent portfolios of the same quality $q$. Their R\&D investments add additional patents to these portfolios. Unblocked patents raise the quality of the portfolios and this raises profits. To formalize this consider the following assumptions.

Let the quality of a patent portfolio be a function of the degree of blocking $(B)$ between patents. Blocking reflects the proportion of patents owned by each firm that overlaps with patents held by the rival firm. We normalize the degree of blocking to be between zero and one: $B \in[0,1]$. If blocking is complete $(B=1)$, then neither the leader nor the follower can use their blocked patents without a licensing contract. If there is no blocking $(B=0)$, firms need not license-in rivals' patents to use their own. For intermediate levels of blocking some of the leader's patents and all of the follower's patents will be blocked. We assume that higher levels of blocking further reduce the quality of the leader's patent stock more:

$$
q(B) \quad \text { where } \quad \frac{\partial q(B)}{\partial B}<0
$$

If firms cross license patents, removing the possibility of blocking, patent stocks are of quality $\tilde{q}(0)$ both under ex ante and ex post licensing. If firms do not cross license patents the leader has a patent stock quality of $\bar{q}(B)$ while the quality of follower's patent stock is $q$ reflecting the fact that all of their new patents are blocked. Note that $\tilde{q}(0) \geq \bar{q}(B)>q$ if $B<1$. Under complete blocking the relative size of firms' patent portfolios is irrelevant to their bargaining strengths since each firm's outside option consists of current profits:

$$
q(1)=q
$$

This assumption captures the case of perfectly complementary patents: if one firm owns one patent on a technology it is able to hold-up the entire stock of the rival firm's new patents.

To capture the effects of patent stock quality on a firm's profits we employ a reduced form representation of profits. We assume each firm's profits $\pi_{i}$ depend on the quality of a firm's own 
patent portfolio and on the quality of its rival's patent portfolio:

$$
\pi_{i}\left(q_{i}, q_{j}\right) \quad \text { where } \quad \frac{\partial \pi_{i}\left(q_{i}, q_{j}\right)}{\partial q_{i}}>0 \quad \text { and } \quad \frac{\partial \pi_{i}\left(q_{i}, q_{j}\right)}{\partial q_{j}} \lesseqgtr 0 \quad \text {. }
$$

We assume own profits increase in the quality of a firm's own patent portfolio. The direct effect of the quality of the rival's patents $\left(q_{j}\right)$ on own profits is nil where the firms produce totally differentiated products. It is negative where they are competitors in the product market and positive where they are complementors in the product market. ${ }^{9}$

Our assumption that firms will share patents, either ex ante or ex post is innocuous as long as firms are not competitors in the product market. If they are competitors, not licensing may be more profitable than licensing as Katsoulacos and Ulph (1998) show. We rule these cases out, allowing us to focus on which type of licensing firms choose. This implies:

$$
2 \pi(\tilde{q}, \tilde{q})>\pi_{l}(\bar{q}, q)+\pi_{f}(q, \bar{q})
$$

where $\pi_{l}$ represents the leader's profits and $\pi_{f}$ the follower's profits.

When both firms raise the quality of patent stocks jointly, we assume the direct effect of such an improvement outweighs any negative indirect effects:

$$
\frac{d \pi_{i}}{d q_{i}}=\frac{\partial \pi_{i}}{\partial q_{i}}+\frac{\partial \pi_{i}}{\partial q_{j}}>0
$$

Our model of R\&D competition is taken from the patent race literature. ${ }^{10}$ The time $(\tau)$ at which firm $i$ becomes the leader is randomly distributed with the exponential distribution:

$$
\operatorname{Pr}(\tau \leq t)=1-e^{-h_{i} t}
$$

where $h_{i}$ represents the hazard rate with which firm $i$ becomes the leader.

The level of each firm's R\&D investment is determined by an R\&D cost function $\gamma\left(h_{i}\right)$. We impose the following conditions on the $\mathrm{R} \& \mathrm{D}$ cost function:

$$
\begin{array}{ll}
\text { (i) } \gamma(0)=\gamma^{\prime}(0)=0, \gamma^{\prime \prime}(0)>0 & \text { (ii) } \forall h_{i}>0: \gamma\left(h_{i}\right)>0, \gamma^{\prime}\left(h_{i}\right)>0, \gamma^{\prime \prime}\left(h_{i}\right)>0
\end{array}
$$

$$
\text { (iii) } \lim _{h_{i} \rightarrow \infty} \gamma^{\prime}\left(h_{i}\right)=\infty \text {. }
$$

\footnotetext{
${ }^{9}$ In Appendix A.2 we demonstrate that these assumptions correspond to the partial effects in a model of linear demand where higher patent stock quality leads to lower marginal cost.

${ }^{10}$ For a survey of this literature refer to Reinganum (1989).
} 
These conditions imply that: (i) firms always find it optimal to invest in R\&D, (ii) the costs of $\mathrm{R} \& \mathrm{D}$ are strictly increasing in the probability of becoming the leader, (iii) no firm can ever be certain that they will be the first to patent if neither firm has yet patented.

\subsection{Stage 3: Ex post bargaining}

We analyze the outcome of ex post bargaining for firms that have not agreed to license ex ante. By assumption (S) firms not already cooperating on R\&D will find it profitable to sign an ex post licensing contract. We assume that the results of ex post bargaining between firms conforms to the Nash bargaining solution.

In absence of a licensing contract the leader's ex post profits are $\pi_{l}(\bar{q}, q)$ and those of the follower are $\pi_{f}(q, \bar{q})$. Once both firms cross-license leader and follower have access to the same technology and their profits are $\pi(\tilde{q}, \tilde{q})$. The expected values of being leader $\left(v_{l}\right)$ and follower $\left(v_{f}\right)$ which conform to the Nash bargaining solution are

$$
v_{l}=\frac{1}{2} \pi_{l}(\bar{q}, q)+\frac{1}{2}\left[\pi(\tilde{q}, \tilde{q})-\pi_{f}(q, \bar{q})\right] \quad \text { and } v_{f}=\frac{1}{2} \pi_{f}(q, \bar{q})+\frac{1}{2}\left[\pi(\tilde{q}, \tilde{q})-\pi_{l}(\bar{q}, q)\right]
$$

and it follows that

$$
v_{l}+v_{f}=\pi(\tilde{q}, \tilde{q}) \quad \text { and } \triangle v \equiv v_{l}-v_{f}=\pi_{l}(\bar{q}, q)-\pi_{f}(q, \bar{q})
$$

These composite values are used further below.

\subsection{Stage 2: R\&D investment}

We derive firms' $R \& D$ investment levels taking into account that they have either signed an ex ante licensing contract or not. If they have signed such a contract the threat of blocking is removed, otherwise firms anticipate ex post bargaining.

\subsubsection{R\&D investments under the shadow of ex post bargaining}

Since firms initially hold patent portfolios of the same quality we solve their R\&D investment problem using a single value function:

$$
V_{p}\left(h_{p}, H_{p}\right)=\frac{\frac{v_{l}}{r} h_{p}+\frac{v_{f}}{r} H_{p}+\pi(q, q)-\gamma\left(h_{p}\right)}{h_{p}+H_{p}+r} \quad,
$$


where $h_{p}$ denotes the hazard rate chosen by each firm, $H_{p}$ is the hazard rate of the firm's R\&D competitor under ex post licensing and $r$ is the discount rate. The value function is derived just as the value functions in models of patent races (Loury, 1979; Reinganum, 1989). The main difference here lies in the complexity of the payoffs $\left(v_{l}, v_{f}\right)$ which reflect the expected values of bargaining ex post.

The first order condition determining the optimal hazard rate $\hat{h}_{p}$ of each firm is:

$$
\frac{\partial V_{p}}{\partial h_{p}}=\frac{1}{\left(h_{p}+H_{p}+r\right)^{2}}\left[\frac{\left(v_{l}-v_{f}\right)}{r} H_{p}+\left[v_{l}-\pi(q, q)\right]+\gamma\left(h_{p}\right)-\gamma^{\prime}\left(h_{p}\right)\left[h_{p}+H_{p}+r\right]\right]=0,
$$

where $\hat{h}_{p}$ and $\hat{H}_{p}$ denote optimal investment levels. Symmetry implies that $\hat{h}_{p}=\hat{H}_{p}$. Assumption $(\mathrm{G})$ on the R\&D cost function implies $\hat{h}_{p}$ is a local maximum. ${ }^{11}$

Following Beath et al. (1989) we identify two innovation incentives in the above expression: the competitive threat and the profit incentive. These incentives determine firms' R\&D investments. The competitive threat is defined as the limit of the first order condition where the R\&D investment of the competing firm is infinite:

$$
\lim _{H_{p} \rightarrow \infty} \frac{\partial V_{p}}{\partial h_{p}}=\frac{\triangle v}{r}-\gamma^{\prime}\left(\bar{h}_{p}\right)=0
$$

It captures the marginal benefit of just pipping the other contestant in the tournament at the post, given that they are almost entirely certain of innovating in the following instant. The competitive threat is the dominant $R \& D$ incentive where $R \& D$ investments are high and innovations occur more frequently. Here $\left(\underline{h}_{p}, \bar{h}_{p}\right)$ represent the limits of the interval from which a firm will choose its equilibrium hazard rate. ${ }^{12}$

The profit incentive is defined as the limit of the first order condition where the R\&D investment of the rival firm $\left(H_{p}\right)$ is zero and the firm is certain of becoming the leader:

$$
\lim _{H_{p} \rightarrow 0} \frac{\partial V_{p}}{\partial h_{p}}=\left[v_{l}-\pi(q, q)\right]+\gamma\left(\underline{h}_{p}\right)-\gamma^{\prime}\left(\underline{h}_{p}\right)\left[\underline{h}_{p}+r\right]=0
$$

Below we derive the comparative statics results from the first order condition (5). Nti (1997) shows that the derivation of comparative statics results here is complicated by the fact that comparative statics results with respect to all contestants in the R\&D tournament are derived.

\footnotetext{
11 Notice that $\frac{\partial^{2} V_{p}}{\partial h_{p}^{2}}=-\left(\frac{\partial^{2} \gamma}{\partial h_{p}^{2}}\right) \frac{1}{h_{p}+H_{p}+r}<0$.

${ }^{12}$ Given assumption (P) above it follows that: $\bar{h}_{p}>\underline{h}_{p}$.
} 
The following first order condition explicitly recognizes the symmetry of all firms ${ }^{13}$

$$
R_{p}\left(B, \hat{h}_{p}\right)=\frac{1}{\left(2 \hat{h}_{p}+r\right)^{2}}\left[\frac{\triangle v}{2 r}\left(2 \hat{h}_{p}+r\right)+[\pi(\tilde{q}, \tilde{q})-\pi(q, q)]+\gamma\left(\hat{h}_{p}\right)-\gamma^{\prime}\left(\hat{h}_{p}\right)\left[2 \hat{h}_{p}+r\right]\right]=0
$$

Note that the first order condition is rewritten such that the profit incentive is more easily compared to the profit incentive under ex ante licensing which we derive below. To do this we make use of the first equality in equations (3) above. Using symmetry the expected value of ex post licensing can be written as:

$$
V_{p}\left(\hat{h}_{p}\right)=\frac{\left(\frac{v_{l}}{r}+\frac{v_{f}}{r}\right) \hat{h}_{p}+\pi(q, q)-\gamma\left(\hat{h}_{p}\right)}{2 \hat{h}_{p}+r}
$$

Competitive threat and profit incentive We briefly discuss the relative strength of the identified innovation incentives as this is an important determinant of our results below. The magnitude of the competitive threat depends on the difference between the values of becoming the leader and the follower in the patent portfolio race in absence of an ex post licensing contract:

$$
\frac{1}{r} \triangle v=\frac{1}{r}\left(\pi_{l}(\bar{q}, q)-\pi_{f}(q, \bar{q})\right)
$$

In contrast the level of the profit incentive is determined by two different effects: the difference between the expected value of an equal share in the new technological opportunity and ex ante profits $(\pi(\tilde{q}, \tilde{q})-\pi(q, q))$ as well as a proportion of the competitive threat $\left(\frac{1}{2} \triangle v\right)$ :

$$
\frac{1}{2} \triangle v+\pi(\tilde{q}, \tilde{q})-\pi(q, q)
$$

Given expressions (8) and (9) a comparison of the relative magnitude of the competitive threat and the profit incentive can now be undertaken:

\section{Proposition 1}

The profit incentive becomes stronger relative to the competitive threat if (i) blocking becomes greater and/or (ii) the degree of product market substitution becomes smaller for $2>r$.

We prove the two parts of Proposition 1 separately:

\footnotetext{
${ }^{13}$ The corresponding second order condition is: $S=-\frac{\partial^{2} \gamma}{\partial \hat{h}_{p}^{2}} \frac{1}{N \hat{h}_{p}+r}<0$.
} 
(i) Given the level of product market competition an increase in blocking reduces the strength of the competitive threat relative to the profit incentive. Full blocking reduces the competitive threat to zero as there is no gain to being the leader in the patent portfolio race; in contrast blocking has no effect on the value of a new technology under licensing $(\pi(\tilde{q}, \tilde{q}))$. In the limit as blocking becomes full $(B \rightarrow 1)$ the profit incentive is reduced but remains positive while the competitive threat falls to zero. Then the profit incentive is greater than the competitive threat.

(ii) Given the level of blocking an increase in the degree of product market substitution affects both parts of the profit incentive. Greater product market substitution increases the difference between the profits of leader and follower $(\Delta v)$ and it reduces the value of an equal share in the new technological opportunity $\pi(\tilde{q}, \tilde{q})$. As long as $2>r$ the first of these effects raises the competitive threat faster than the profit incentive. Additionally, the second effect reduces the profit incentive. In sum an increase in product market substitution raises the competitive threat faster than the profit incentive.

An intuitive way of thinking about these results is that higher blocking reduces competitive pressure in the patent portfolio race, while higher degrees of product market substitution increase competitive pressure in the patent portfolio race.

Next we analyze how the relative strength of profit incentive and competitive threat determines expected profits from licensing ex ante and ex post.

\subsubsection{R\&D investments after ex ante licensing}

In industries where firms face patent thickets ex ante licensing is usually an instrument intended to ensure freedom to operate. It is not intended to help firms coordinate research activities (Grindley and Teece, 1997; Shapiro, 2001; Parchomovsky and Wagner, 2005). Therefore, we assume that firms undertake independent $R \& D$ investments under ex ante licensing. We show here that ex ante licensing without $\mathrm{R} \& \mathrm{D}$ coordination eliminates the competitive threat as an innovation incentive. Our main results derive from this effect.

The value function for ex ante licensing takes the following form:

$$
V_{a}\left(h_{a}\right)=\frac{\frac{\pi(\tilde{q} \tilde{q})}{r}\left(h_{a}+H_{a}\right)+\pi(q, q)-\gamma\left(h_{a}\right)}{h_{a}+H_{a}+r},
$$

where $h_{a}$ is the hazard rate chosen by firms under ex ante contracting and $\pi(q, q)$ are profits of 
a member firm from its current products. This value function captures the fact that each firm party to the ex ante contract will receive an equal share of ex post profits from the technology, irrespective of who wins the patent portfolio race. Here the symmetric first order condition is:

$$
R_{a}\left(\hat{h}_{a}\right)=\frac{1}{\left(2 \hat{h}_{a}+r\right)^{2}}\left[(\pi(\tilde{q}, \tilde{q})-\pi(q, q))+\gamma\left(\hat{h}_{a}\right)-\gamma^{\prime}\left(\hat{h}_{a}\right)\left(2 \hat{h}_{a}+r\right)\right]=0 .
$$

Assumption $(G)$ on the R\&D cost function implies that $\hat{h}_{a}$ marks an interior optimum. ${ }^{14}$ Note again that the level of $R \& D$ investments undertaken by firms under ex ante licensing is determined only by the profit incentive. The profit incentive under ex post licensing and ex ante licensing are equal in magnitude when blocking is complete $(\triangle v=0)$.

Each firm's expected value of the ex ante contract in equilibrium is:

$$
V_{a}\left(\hat{h}_{a}\right)=\frac{\frac{\pi(\tilde{q}, \tilde{q})}{r} 2 \hat{h}_{a}+\pi(q, q)-\gamma\left(\hat{h}_{a}\right)}{2 \hat{h}_{a}+r}
$$

In this section we have shown that $R \& D$ investments under ex ante licensing are not affected by blocking while those under ex post licensing are. The next section shows how this finding affects the choice between ex ante and ex post licensing at the first stage of the game.

\section{The choice between ex ante and ex post licensing}

In this section the choice between ex ante and ex post licensing is studied. First, we show when the expected values of ex ante and ex post licensing are identical. Thereafter, we investigate which types of licensing contract will predominate as the blocking strength and the intensity of product market competition vary. Finally, we discuss implications of our results.

\subsection{An indifference result}

A comparison of the expected values of ex ante- (12) and ex post licensing (7) in previous sections yields the following result:

\section{Proposition 2}

Ex ante and ex post licensing are of equal value if new patents are completely blocked $(B=1)$.

Next we prove that the competitive threat is zero and the profit incentives of ex ante and ex post licensing are equal when blocking is complete. To see that the competitive threat is

$$
14 \frac{\partial^{2} V_{r}}{\partial h_{r}{ }^{2}}=-\frac{\partial^{2} \gamma}{\partial h_{r}^{2}} \frac{1}{h_{r}+r}<0
$$


zero, note that by Assumption (Q) complete blocking implies that the leader cannot make use of any patents they have acquired without a license to the patents of the follower: $\bar{q}(1)=q$. Therefore, in absence of a licensing contract, the expected values of becoming leader and follower are identical: $v_{l}=v_{f}$. This implies that the competitive threat is zero. Notice also that the profit incentive will still be positive if $\tilde{q}>q$. As noted above the profit incentives under ex ante and ex post licensing are identical if the competitive threat is zero which implies: $\hat{h}_{p}=\hat{h}_{a}$.

Firms invest equally under ex ante and ex post licensing if blocking is complete. Complete blocking also implies that $V_{a}=V_{p}$ as $\frac{v_{l}+v_{f}}{r}=2 \frac{\pi(\tilde{q}, \tilde{q})}{r}$. The intuition for identical values of ex ante and ex post licensing under full blocking is that this removes any threat that firms may emerge with asymmetric payoffs ex post and reduces the competitive threat to zero.

\subsection{Variation in the degree of blocking $(B)$}

In this section we investigate which form of licensing is preferred if blocking is not complete.

\section{Proposition 3}

Two firms will always prefer ex post licensing over ex ante licensing if the profit incentive is stronger than the competitive threat and blocking is not complete. If the competitive threat is stronger than the profit incentive ex ante licensing can be more valuable than ex post licensing.

Increases in the competitive threat arise as blocking is reduced from full blocking towards no blocking. This increases firms' R\&D investments. Proposition 3 states that once the competitive threat becomes sufficiently strong further increases in this innovation incentive raise R\&D investments more than expected benefits from patenting sooner. This reduces the value of ex post licensing and may make it less profitable than ex ante licensing.

Proposition 1 states that the profit incentive will outweigh the competitive threat if (i) the degree of blocking is high, and/or (ii) the degree of product market substitution is low. In conjunction with Proposition 3 this implies that:

\section{Corollary 1}

If the degree of product market substitution between firms' products declines, the value of ex post licensing rises relative to the value of ex ante licensing.

Also:

\section{Corollary 2}

If the degree of blocking rises, the value of ex post licensing rises relative to the value of ex ante licensing. 
Additionally, we can show that:

\section{Proposition 4}

If blocking is close to complete $(B>B(\xi=0))$ any increase in the degree of blocking reduces the difference between the expected value of ex post and ex ante licensing.

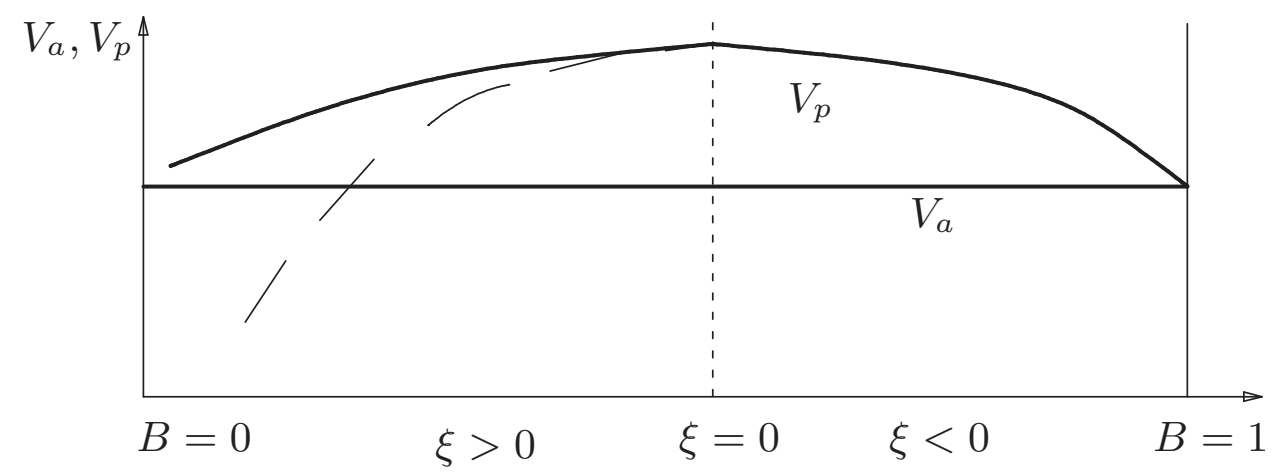

Figure 1: The expected values of ex ante and ex post licensing as the degree of blocking varies.

To illustrate these results we provide Figure 1 above. It shows the expected value of ex ante licensing, which is unaffected by variation in blocking. It also shows the expected value of ex post licensing which is a concave function in blocking $(B) . \xi$ reflects the relative weight of the competitive threat and the profit incentive. It is defined in Equation (13) just below. According to Proposition 3 ex post licensing is always more valuable than ex ante licensing if $\xi<0$ and $B<1$. We show that the expected value of ex ante licensing can become greater than that of ex post licensing where $\xi>0$ - this is illustrated by the dashed line in Figure 1.

To prove Proposition 3 we derive the effect of variation in the blocking strength $(B)$ on the expected value of ex post licensing:

$$
\begin{aligned}
& \frac{\partial V_{p}}{\partial B}=\frac{\partial}{\partial \hat{h}_{p}}\left(\frac{\frac{\pi(\bar{q}, \bar{q})}{r} 2 \hat{h}_{p}+\pi(q, q)-\gamma\left(\hat{h}_{p}\right)}{2 \hat{h}_{p}+r}\right) \frac{\partial \hat{h}_{p}}{\partial B} \\
&=\frac{1}{\left(2 \hat{h}_{p}+r\right)^{2}}\left(2[\pi(\bar{q}, \bar{q})-\pi(q, q)]+2 \gamma\left(\hat{h}_{p}\right)-\gamma^{\prime}\left(\hat{h}_{p}\right)\left(2 \hat{h}_{p}+r\right)\right) \frac{\partial \hat{h}_{p}}{\partial B} \\
&=-\frac{1}{\left(2 \hat{h}_{p}+r\right)} \underbrace{\left[\frac{\triangle v}{r}-\gamma^{\prime}\left(\hat{h}_{p}\right)\right]}_{\xi} \frac{\partial \hat{h}_{p}}{\partial B},
\end{aligned}
$$

where we make use of the first order condition in equation (6) to substitute out terms. The sign of this expression depends on $\xi$ and on the effect of blocking on the equilibrium level of investment by firms under ex post licensing $\left(\hat{h}_{p}\right)$. In Appendix A.1 we show that greater blocking reduces firms' R\&D investments under ex post licensing if two firms produce substitute products: 
$\frac{\partial \hat{h}_{p}}{\partial B}<0$. We investigate the sign of $\xi$ here.

In general $\xi$ may be positive or negative. Rewriting Equation (6) we can show that:

$$
\underbrace{\left(\frac{\triangle v}{r}-\gamma^{\prime}\left(\hat{h}_{p}\right)\right)}_{\xi}\left[2 \hat{h}_{p}+r\right]=\frac{1}{2} \frac{\triangle v}{r}\left(2 \hat{h}_{p}+r\right)-[\pi(\bar{q}, \bar{q})-\pi(q, q)]-\gamma\left(\hat{h}_{p}\right)
$$

$\xi$ is positive if the competitive threat is sufficiently larger than the profit incentive. As noted in Section 2.3.1 above this holds if firms produce substitutable products and/or blocking is low. Whether any of these factors is sufficiently strong for ex ante licensing to be more profitable than ex post licensing at any level of blocking depends on the functional form of the demand function. Section 4 shows for which parameter combinations under linear demand ex ante or ex post licensing is prefered. These simulations provide confirmation of our analytical results and illustrate the effects of variation in product market substitution on $R \& D$ investments.

So far we have shown that locally, the expected value of ex post licensing is greater than the expected value of ex ante licensing if the degree of blocking is high. We also show that in cases in which the degree of blocking is sufficiently low, the competitive threat can outweigh the profit incentive. Now consider a decrease in blocking from, complete blocking towards no blocking at all. At first $V_{a}=V_{p}$ (Proposition 2), then $\left(V_{p}>V_{a}\right)$ (Proposition 3) and $V_{p}$ will be increasing as long as $\xi<0$. If the competitive threat becomes large enough $\xi>0$ will begin to hold and the expected value of ex post licensing decreases.

Next we show that $V_{a}>V_{p}$ if the competitive threat becomes sufficiently important:

$$
\begin{array}{r}
V_{a}-V_{p} \geq 0 \\
\Leftrightarrow\left[\gamma\left(\hat{h_{p}}\right)-\gamma\left(\hat{h}_{a}\right)\right]\left(2 \hat{h}_{a}+r\right) \geq 2\left(\hat{h}_{p}-\hat{h}_{a}\right) \underbrace{\left[(\pi(\tilde{q}, \tilde{q})-\pi(q, q))+\gamma\left(\hat{h}_{a}\right)\right]}_{\text {P.I. }} \\
\Leftrightarrow \frac{\left[\gamma \left(\hat{\left.\left.h_{p}\right)-\gamma\left(\hat{h}_{a}\right)\right]}\right.\right.}{\left(\hat{h}_{p}-\hat{h}_{a}\right)} \geq 2 \gamma^{\prime}\left(\hat{h}_{a}\right),
\end{array}
$$

where we use Equation (11) at the second step. Under the conditions of Proposition 3 equilibrium $\mathrm{R} \& \mathrm{D}$ investments under ex post licensing $\left(\hat{h}_{p}\right)$ grow as the expectation of blocking $(B)$ decreases. Equation (15) shows that the expected value of ex ante licensing is greater than that of ex post licensing if the competitive threat outweighs the profit incentive sufficiently. Then, the average gradient of the cost function between $\hat{h}_{p}$ and $\hat{h}_{a}$ is greater than twice the 


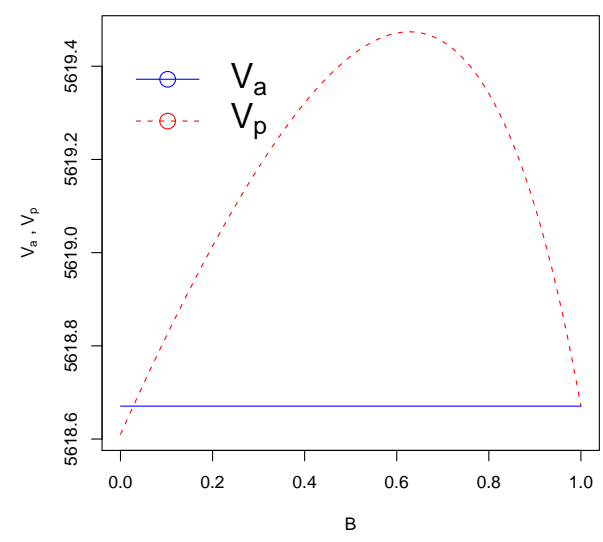

(a) Complements: $a=100 ; \bar{c}=80 ; \delta c=4 ; \sigma=-0.45$

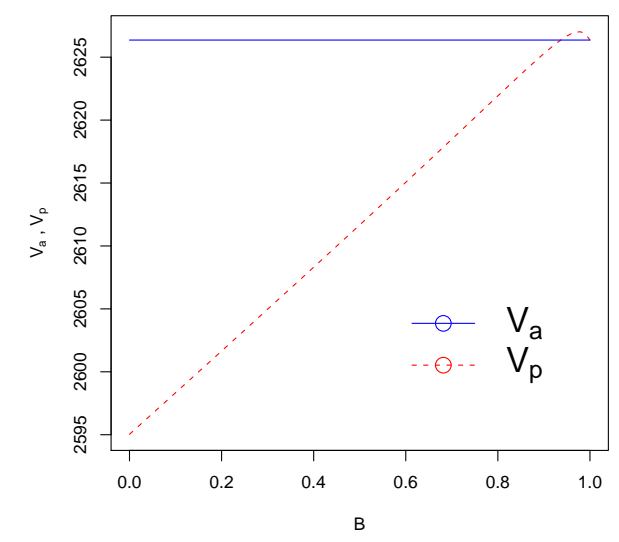

(b) Substitutes:

$a=100 ; \bar{c}=80 ; \delta c=4 ; \sigma=0.45$

Figure 2: Values of ex ante and ex post licensing as blocking varies, given moderate levels of product market complementarity (a) and substitution (b).

derivative of the cost function at $\hat{h}_{a}$. These conditions are most likely fulfilled if the degree of blocking is not high and products are substitutes in the product market (Proposition 2). Then the competitive threat is strong and $\mathrm{R} \& \mathrm{D}$ investments under ex post licensing are high.

\section{Simulation results}

In this section we illustrate the analytical results from the previous section using simulation and test the robustness of the model. We simulate our model in R ( R Development Core Team, 2008). Several graphs illustrate the results of these simulations. ${ }^{15}$

Proposition 1 clarifies that the relative strength of the competitive threat and the profit incentive depends on two exogenous factors: (i) the degree of blocking and (ii) the degree of product market substitution. The simulations set out here reveal the impact of each of these factors on the values of ex ante and ex post licensing. We provide two dimensional graphs of the value of ex ante and ex post licensing as blocking varies over the interval $[0,1]$. These graphs illustrate simulations of the theoretical model which show how variation of the competitive threat affects the probability of observing ex ante licensing. Additionally, we test the robustness of our model and relax the assumption maintained above that only the leader receives unblocked patents. The results of this simulation show that the predictions of the model are not affected by the assumption that only the leader receives unblocked patents.

\footnotetext{
${ }^{15}$ The code for the two dimensional graphs is provided in Appendix A.2 using Sweave (Leisch, 2002). This code can be run in $\mathrm{R}$ to duplicate our results and further explore the model.
} 
Figure 2 illustrates effects of blocking under moderate complementarity $(\sigma=-0.45)$ and under moderate substitutability $(\sigma=0.45)$ of products. New patents, if unblocked, lead to a cost reduction of $5 \%(\delta c=4$ given $\bar{c}=80)$. Figures $2(\mathrm{a})$ and 2(b) show ex ante and ex post licensing have the same expected values if blocking is complete $B=1$. Figure 2(a) shows that ex-post licensing is always more profitable if products are moderate complements, while Figure 2(b) shows that ex ante licensing is mostly more profitable if products are substitutes.

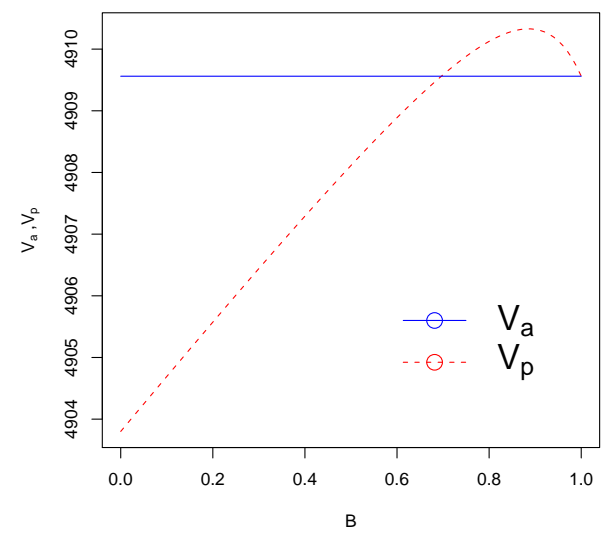

(a) Complements:

$a=100 \bar{c}=80 ; \delta c=4 ; \sigma=-0.33$

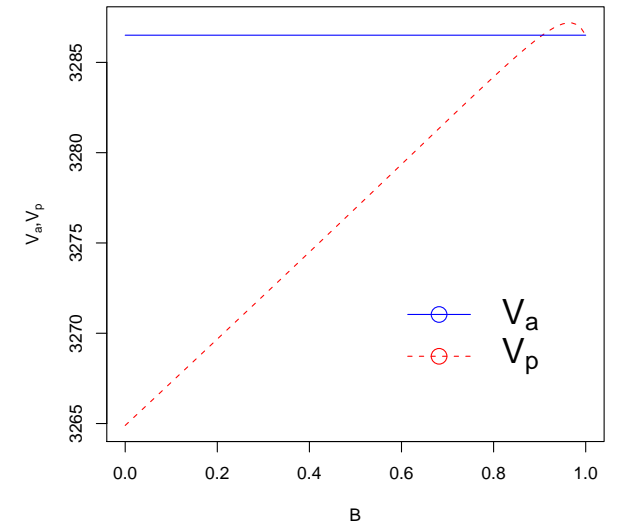

(b) Substitutes:

$a=100 \bar{c}=80 ; \delta c=4 ; \sigma=0.11$

Figure 3: Values of ex ante and ex post licensing as blocking varies, given low levels of product market complementarity (a) and substitution (b).

In Figures 3(a) and 3(b) we illustrate the effects of an increase (3(a)) and a reduction (3(b)) of the substitutability of firms' products. By Proposition 1 an increase in the degree of product market substitution strengthens the competitive threat relative to the profit incentive. By Proposition 3 and Corollary 1 this is predicted to make ex ante licensing more likely. A comparison of Figures 2(a) and 3(a) shows that ex ante licensing is more profitable than ex post licensing for a larger range of blocking as products become stronger substitutes. Figures 2(b) and 3(b) demonstrate the opposite is true for products becoming stronger complements.

To summarize, Figures 2 and 3 show how blocking and product market substitution affect the relative values of ex ante and ex post licensing. The comparative statics illustrate in these figures confirm the analytical results contained in our Propositions.

Figures 4(a) and 4(b) provide a robustness check of our model. We investigate how the setting in Figures 2(a) and 2(b) is altered if both leader and follower are able obtain patents that are unblocked. This would correspond to the case in which both leader and follower can 


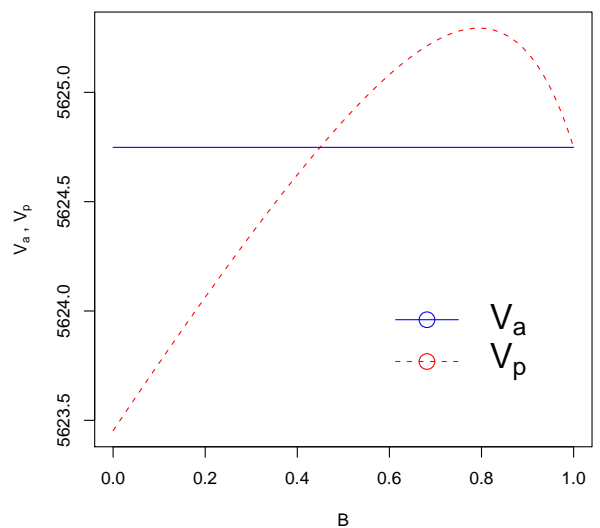

(a) Complements:

$a=100 \bar{c}=80 ; \delta c=4 ; \sigma=-0.45$

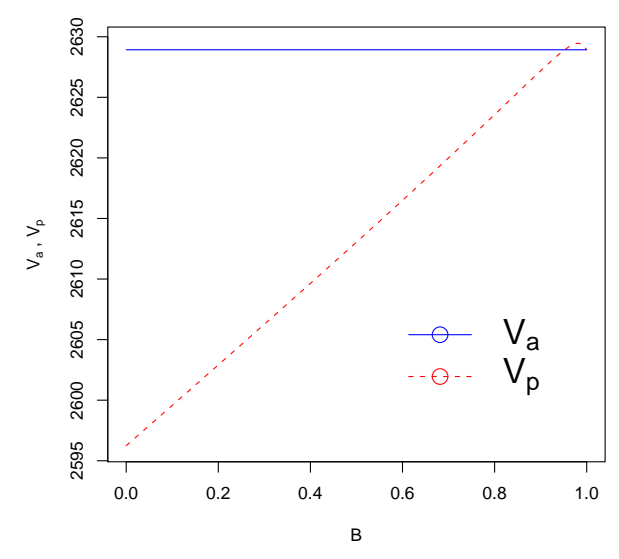

(b) Substitutes:

$a=100 \bar{c}=80, \delta c=0.5, \sigma=0.45$

Figure 4: Robustness check allowing the follower to obtain unblocked new patents.

Values of ex ante and ex post licensing as blocking varies, given moderate levels of product market complementarity (a) and substitution (b).

reduce their costs in the face of blocking. A comparison of Figures 2 and 4 shows this reduction of the profit incentive makes ex ante licensing more likely.

\section{Empirical specification and results}

This section provides an empirical test of the main theoretical results derived above. We focus on firms' propensity to license ex ante or ex post depending on the degree of blocking and the degree of product market competition. First, several hypotheses are presented along with an empirical specification to test these. Next, we discuss the semiconductor industry and the data we use. Finally, results of estimation of the empirical model are presented and discussed.

\subsection{Hypotheses and empirical specification}

According to the theoretical model, the values of ex ante and ex post licensing depend on the degree of blocking and the degree of product market competition. We derive two hypotheses from Corollaries 1 and 2. We have shown that ex ante licensing will only be observed if blocking is low. Therefore we expect that:

\section{Hypothesis 1}

Firms are more likely to enter into ex ante licensing agreements if the degree of blocking between their patents is lower. 
Our theoretical model also shows that a higher (lower) degree of product market competition increases incentives to license ex ante (ex post). We expect that:

\section{Hypothesis 2}

Firms are more likely to enter into ex ante licensing agreements if the degree of product market competition between those firms is more intense.

We also account for transaction costs firms incur when they license. Grindley and Teece (1997) highlight the fact that licensing involves significant costs and managerial effort. Hence, firms signing up for licensing agreements incur transaction costs when licensing. Ex ante and ex post licensing contracts differ and firms will learn to implement each type of contract separately. Consequently, we assume that transaction costs decrease in firms' prior experience of having been engaged in each type of licensing:

\section{Hypothesis 3}

The probability of observing ex ante (ex post) licensing increases in firms' experience of ex ante (ex post) licensing.

\subsubsection{Empirical model}

Most licensing agreements in our dataset are signed between two firms. For this reason, we concentrate our analysis on firm pairs and estimate the likelihood $\Pi_{a, i j, t}^{*}$ that two firms $i$ and $j$ form an ex ante licensing agreement in period $t$, where $\Pi_{a, i j, t}^{*}>0$ if the firms form an ex ante licensing contract, and $\Pi_{a, i j, t}^{*} \leq 0$ if the firms form an ex post licensing contract. ${ }^{16}$ The empirical specification is:

$$
\begin{aligned}
\Pi_{a, i j}^{*}=\alpha_{1} B_{i j} & +\alpha_{2} P M C_{i j}+\alpha_{3} T_{a, i j}+\alpha_{4} T_{p, i j} \\
& +\alpha_{5} R_{i j}+\alpha_{6} A S M S_{i j}+\alpha_{7} D S M S_{i j}+\alpha_{8} A S P S_{i j}+\alpha_{9} T I M E_{i j}+\varepsilon_{i j}
\end{aligned}
$$

The right hand side of this equation contains the following firm pair specific variables: degree of blocking $\left(B_{i j}\right)$, the degree of product market competition $\left(P M C_{i j}\right)$, and firms' costs of licensing ex ante and ex post $\left(T_{a, i j}\right.$ and $\left.T_{p, i j}\right)$. The specification also includes the following control variables: ${ }^{17}$ revenues in the semiconductor industry $\left(R_{i j}\right)$, firms' average semiconductor market shares $\left(A S M S_{i j}\right)$, firms' difference in semiconductor market shares $\left(D S M S_{i j}\right)$, firms'

\footnotetext{
${ }^{16}$ Note that in order to simplify notation we drop the time index $t$ for all variables from now onwards.

17 The control variables are in line with previous empirical literature on licensing. We introduce the variable definitions in the next section.
} 
average semiconductor patent stocks $\left(A S P S_{i j}\right)$ and a time trend $\left(T I M E_{i j}\right){ }^{18}$ We estimate equation (16) by probit. Next, we describe the industry and the dataset we use.

\subsection{Industry and data}

The hypotheses presented above are tested using data on the semiconductor industry from 1989 to 1999. Semiconductors are mainly used as inputs for computers, consumer electronics, and communications equipment. Semiconductors can be categorized into memory chips, micro components, and other components such as logic, discrete and optical devices. The market for semiconductors is characterized by companies that operate worldwide. Revenues generated by the industry in 1999 reached 168.9 Billion US-\$.

The semiconductor is a high tech industry in which innovation determines firms' success and survival in the market. The industry is characterized by rapid technological change and cumulative innovation and is affected by patent thickets (Hall and Ziedonis, 2001; Ziedonis, 2004; von Graevenitz et al., 2008). Firms continually make large investments in research and development in their attempts to stay at the frontier of new technology. Research spending as a percentage of sales (13\%) outranks many other industries such as pharmaceuticals and the computer industry. The number of US-patent applications in semiconductor related patent classes tripled throughout the nineties. This reflects the importance of innovation for semiconductor firms but also strategic patenting by the industry (Hall and Ziedonis, 2001; Ziedonis, 2004). Technology for semiconductors has become increasingly complex over time, as downstream industries such as computers and telecommunications have fostered demand for more advanced chips. Moreover, shorter product life cycles have required firms to keep up with the increasing pace of innovation and the necessity to recoup R\&D investments in shorter time periods. Increasingly complex and cumulative technologies have inevitably led to overlapping developments and mutually blocking patents as competing products draw on related technologies. Multiple firms develop patented innovations in the same technological fields, and the "state of the art" of the technology tends to be covered by a large number of patents held by different firms. To ensure "freedom-to-operate" in innovation and manufacturing, it has become essential to license large numbers of patents (Grindley and Teece, 1997; Lichtenthaler, 2007).

Our dataset is based on data from a variety of different sources. ${ }^{19}$ Firm-level information on

\footnotetext{
${ }^{18}$ Note that we also run our regression using time dummies instead of a time trend and find no significant differences.

19 Siebert and von Graevenitz (2008) provide a detailed descriptive analysis of the data.
} 
licensing contracts in the semiconductor industry are provided by Thompson Financial. This licensing dataset contains information on the date and the participating firms in a licensing contract as well as a description of the agreement. From this database we extract horizontal licensing agreements, i.e. licensing contracts that have been signed between two semiconductor firms. We deselect 22 licensing contracts signed in the context of litigation.

\section{Table 1: Number of licensing contracts and patents (1989-1999)}

\begin{tabular}{|c||cccc|}
\hline Year & Licensing & Ex ante licensing & Ex post licensing & Semiconductor patents \\
\hline 1989 & 43 & 22 & 21 & 4,063 \\
1990 & 74 & 38 & 36 & 4,521 \\
1991 & 110 & 83 & 27 & 5,276 \\
1992 & 115 & 77 & 38 & 5,313 \\
1993 & 117 & 86 & 31 & 5,688 \\
1994 & 135 & 103 & 32 & 7,554 \\
1995 & 85 & 58 & 27 & 9,250 \\
1996 & 34 & 22 & 12 & 10,390 \\
1997 & 67 & 40 & 27 & 13,507 \\
1998 & 37 & 12 & 25 & 13,080 \\
1999 & 30 & 8 & 22 & 12,624 \\
\hline Total & 847 & 549 & 298 & 91,266 \\
\hline \hline
\end{tabular}

This table displays the total number of licensing contracts as well as ex ante licensing and ex post licensing contracts signed between semiconductor firms (Data source: Thompson Financial). The table also shows the number of semiconductor patents filed (Data source: NBER database). Note that the technological classes defining the semiconductor industry are mentioned in the text.

This leaves us with 847 licensing contracts that were signed between 1989 and 1999 ( see Table 1). The large number of licensing contracts confirms the view that licensing is widespread in the semiconductor industry. It is interesting to note that the number of licensing deals increased from 43 in 1989 to 135 in 1994 indicating that licensing became increasingly important in the early and mid nineties. We classify the licensing contracts into ex ante and ex post licensing according to their descriptions. The resulting dataset contains 549 ex ante and 298 ex post licensing contracts. Table 1 shows that the number of ex ante licensing deals follows an 
inverse U-shape over time, reflecting the fact that ex ante licensing was frequent in the mid 90's. In contrast, the number of ex post licensing agreements remained relatively stable throughout the years. Hence, most variation of licensing is due to the larger variation of ex ante licensing.

We also use annual firm-level market shares and revenues provided by Gartner Group over the period 1989 to 1999. The market share database contains 268 firms and reports their market shares and revenues for the semiconductor industry overall, as well as different segments, such as memory chips, microcomponents and other devices.

Finally, we use firm-level patent information in the semiconductor industry taken from the NBER database established by Hall et al. (2005). The patent database includes detailed information on approximately 3 million US utility patents that were applied for and subsequently granted in the US between 1963 and 1999. It also holds more than 16 million citations made between 1975 and 1999. Following Hall et al. (2005) we are able to identify the following nine technology classes as referring to the semiconductor industry, i.e. 257;326; $438 ; 505$ (semiconductor manufacturing), 360;365; 369; 711 (memory) and 714 (microcomponents). As the technology classes are mentioned on every patent we were able to establish the number of patent applications in the semiconductor industry. As shown in Table 1, the number of semiconductor patents increased from 4,063 in 1989 to 12,624 in 1999. The increasing number of patents emphasizes a higher innovation and patenting rate in the 1990's, as reported in Hall and Ziedonis (2001). Moreover, the higher number of patents parallels the increasing number of licensing contracts. This suggests that licensing might have been used to cut through the patent thicket in order to preserve freedom to operate as argued by Grindley and Teece (1997).

\subsection{Definition of variables and descriptive statistics}

Next we discuss the definition of the variables included in the empirical model (Equation 16). ${ }^{20}$

\section{Ex ante and ex post licensing $\left(\Pi_{a}\right)$}

The variable, $\Pi_{a}$, is a binary variable and takes on the value of 1 , if two firms engage in an ex ante licensing contract and 0 if the firms entered into an ex post licensing agreement in a specific period $t$.

\section{Blocking}

We define a blocking measure $B_{i j, t}$ between two firms $i$ and $j$ in period $t$. The measure

\footnotetext{
${ }^{20}$ Note again, that we construct all our variables based on firm pairs and drop sub-indices that refer to firm pairs and time periods. We also drop the subscript $t$ from now onwards in order to simplify notation.
} 
proxies the extent to which firms' innovations are interlinked with each other which is the precondition for a hold-up problem to exist. Technologically more similar innovations and higher cross citations between patents of two firms reflect a higher inter-linkage of firms' technologies. Hence, we define our blocking variable as the interaction between firms' technological similarity $\left(S_{i j}\right)$ and their citation intensity $\left(C_{i j}\right)$ as follows: ${ }^{21}$

$$
B_{i j}=S_{i j}\left(C_{i j}+C_{j i}\right)
$$

The variable takes on larger values for higher degrees of blocking.

Technological similarity $\left(S_{i j}\right)$ captures technological relatedness of firms. The measure is based on the distribution of firms' patents across nine technology classes $(c)$ that characterize the semiconductor industry, as previously discussed. We construct the variable using the uncentered correlation coefficient as suggested by Jaffe (1986): ${ }^{22}$

$$
S_{i j}=\frac{\sum_{c=1}^{9} A_{i}^{c} A_{j}^{c}}{\sqrt{\sum_{c=1}^{9} A_{i}^{c}} \sqrt{\sum_{c=1}^{9} A_{j}^{c}}} .
$$

where $(A)$ indicates the number of a firm's patent applications.

Citation intensity $\left(C_{i j}\right)$ measures direct linkages across firms' patents and is defined as the number of citations of firm $i^{\prime} s$ patents that point to patents belonging to firm $j$ relative to the total number of firm $i$ 's citations:

$$
C_{i j}=\frac{c_{i j}}{\sum_{k} c_{i k}}
$$

where $k \in K$ with $K$ being the total number of firms and $c_{i k}$ is the number of citations of firm $k$ by firm $i$.

Table 2 reports the means of the blocking variable over time for different subsets of our data. The table shows that blocking intensity between firms increased sharply until the mid 90's. It is interesting to see that the blocking variable is higher in the sample which is used for our analysis (All licensing pairs) than in the sample of innovating firms in the semiconductor industry overall (All pairs). This shows that firms that cross license are affected by a higher

\footnotetext{
${ }^{21}$ Since patent citations partly serve to delineate the state of the art on which a patent builds, a higher level of mutual citations indicates that each firm has patents which reduce the scope of the rival firm's patents. This is likely to be a greater problem if the two firms also hold patents on similar technologies as indicated by the distribution of patents across patent classes $\left(S_{i j}\right)$.

22 This measure of technological similarity is widely used to capture technological proximity, see e.g. Bloom et al. (2005) and Schankerman and Noel (2006) among many others.
} 
degree of blocking. The table also shows substantial variation of the blocking measure over time for firms that engaged in ex ante licensing (column 4) as well as for firms that engaged in ex post licensing (column 5).

Table 2: Degree of blocking $(B)$ over time

\begin{tabular}{|l||cccc|}
\hline Year & All pairs & $\begin{array}{c}\text { All licensing } \\
\text { pairs }\end{array}$ & $\begin{array}{c}\text { Ex ante licensing } \\
\text { pairs }\end{array}$ & $\begin{array}{c}\text { Ex post licensing } \\
\text { pairs }\end{array}$ \\
\hline 1989 & 0.0001 & 0 & 0 & 0 \\
1990 & 0.001 & 0.001 & 0.002 & 0.001 \\
1991 & 0.003 & 0.003 & 0.008 & 0.003 \\
1992 & 0.005 & 0.005 & 0.005 & 0.007 \\
1993 & 0.005 & 0.007 & 0.012 & 0.006 \\
1994 & 0.006 & 0.016 & 0.007 & 0.012 \\
1995 & 0.007 & 0.009 & 0.013 & 0.011 \\
1996 & 0.006 & 0.013 & 0.015 & 0.009 \\
1997 & 0.009 & 0.024 & 0.023 & 0.028 \\
1998 & 0.006 & 0.006 & 0.016 & 0.004 \\
1999 & 0.015 & 0.003 & n.a. & 0.005 \\
\hline $\mathrm{N}$ & 35,778 & 476 & 212 & 264 \\
\hline
\end{tabular}

This table displays the means of our blocking variable over time. The blocking variable is constructed using patent information from the NBER patent database. Column 2 refers to the mean of the blocking variable for all innovating firm pairs in the semiconductor industry. Columns 3-5 refer to means of the blocking measure for firm pairs entering our analysis.

In using the blocking measure we take account of the fact that the decision on the kind of licensing contract chosen is made at a different point in time relative to the date of an ex ante and an ex post licensing contract which we observe. The decision to license ex ante is the date of singing of the contract we observe. Therefore, ex ante contracts in period $t$ will be related to the contemporaneous level of blocking in period $t$.

In the case of ex post licensing, the decision not to license ex ante is made much before the date of signing of the contract we observe. Consequently, an ex post licensing agreement needs 
to be related to the blocking measure in the past, e.g. in period $t-1$. We also use the degree of blocking in period $t$ to test the robustness of our timing assumption $(\tilde{B})$.

\section{Table 3: Product market competition $(P M C)$ over time}

\begin{tabular}{|l||cccc|}
\hline Year & All pairs & All licensing & Ex ante licensing & Ex post licensing \\
& & pairs & pairs & pairs \\
\hline 1989 & 0.111 & 0.412 & 0.249 & 0.448 \\
1990 & 0.125 & 0.468 & 0.473 & 0.466 \\
1991 & 0.115 & 0.558 & 0.518 & 0.597 \\
1992 & 0.155 & 0.553 & 0.638 & 0.506 \\
1993 & 0.143 & 0.539 & 0.525 & 0.569 \\
1994 & 0.143 & 0.499 & 0.472 & 0.519 \\
1995 & 0.178 & 0.452 & 0.531 & 0.396 \\
1996 & 0.147 & 0.815 & 0.867 & 0.606 \\
1997 & 0.174 & 0.716 & 0.572 & 0.955 \\
1998 & 0.204 & 0.708 & 0.784 & 0.618 \\
1999 & 0.165 & 0.235 & n.a. & 0.235 \\
\hline $\mathrm{N}$ & 35,778 & 476 & 212 & 264 \\
\hline \hline
\end{tabular}

This table displays the means of our product market competition variable over time. The variable is constructed using market share information provided by Gartner Group. Column 2 refers to the mean of the product market competition variable for all producing firm pairs in the semiconductor industry. Columns 3-5 refer to the means of firm pairs, which enter our regression analysis.

\section{Product market competition}

Another important variable in our empirical analysis is the degree of product market competition. Our measure of product market competition is based on firms' market shares in three different semiconductor segments: memory, microcomponents and other devices. Following Bloom et al. (2005), we use the uncentered correlation measure to measure product market competition within each firm pair: 


$$
M_{i j}=\frac{\sum_{l=1}^{3} m s_{l i} * m s_{l j}}{\sqrt{\sum_{l=1}^{3} m s_{l i}^{2}} \sqrt{\sum_{l=1}^{3} m s_{l j}^{2}}} .
$$

Here $m s$ denotes market shares, and $l=1,2,3$ indicates the three market segments. The variable takes on values close to zero, if firms have sales in different market segments. It takes on values close to one if firms are active in the same market segments with similar market shares.

Table 3 reports the means of the product market competition $(P M C)$ variable over time for all producing firm pairs in the semiconductor industry (column 2). We also report the means of the variable for firm pairs that engaged in licensing overall (column 3), as well as separated by ex ante licensing (column 4) and ex post licensing (column 5). The table shows that the degree of product market competition increased over time for all four different groups of firm pairs. Moreover, firm pairs which engaged in licensing (columns 3-5) are characterized by a higher degree of product market competition than firm pairs overall (column 2).

Table 4: Descriptive statistics for all licensing pairs $(\mathrm{N}=476)$

\begin{tabular}{|l||cccc|}
\hline Variable & Mean & Std. dev. & Min. & Max. \\
\hline$\Pi_{a}$ & 0.445 & 0.498 & 0 & 1 \\
$B$ & 0.007 & 0.012 & 0 & 0.088 \\
\multirow{2}{*}{$P M C$} & 0.546 & 0.403 & 0 & 1 \\
$T_{a}$ & 8.869 & 6.918 & 0 & 36 \\
$T_{p}$ & 7.714 & 7.491 & 0 & 39 \\
$R$ & $89,031.81$ & $37,439.27$ & 52,751 & 169,311 \\
$A S M S$ & 0.032 & 0.021 & 0 & 0.099 \\
$D S M S$ & 0.028 & 0.027 & 0 & 0.164 \\
$A S P S$ & 543.332 & 536.211 & 0 & 3,292 \\
\hline \hline
\end{tabular}

This table displays the descriptive statistics of the variables used in our regression analysis.

We use all observations that finally enter the regression analysis.

Experience and transaction costs $\left(T_{a}, T_{p}\right)$

We do not observe transaction costs but use firms' experience in ex ante and ex post licensing 
contracts as a proxy. Experience with licensing will lower the cost of subsequent licensing deals. Firms' experience is measured as the count of previous ex ante and ex post licensing contracts signed, denoted by $T_{a}$ and $T_{p}$, respectively.

Product and R\&D market characteristics ( $R, A S M S, D S M S, A S P S)$

We also control for industry revenues $(R)$, firms' average semiconductor market shares $(A S M S)$, firms' differences in semiconductor market shares $(D S M S)$, and the average patent shares $(A S P S)$ in the semiconductor industry.

Time trend (TIME)

The TIME variable indicates a time trend that starts at 1 in the year 1989 and runs up to 11 for 1999.

Table 5: Descriptive statistics by type of licensing contract $(\mathrm{N}=476)$

\begin{tabular}{|l||cccc|cccc|}
\hline \multicolumn{1}{|c||}{} & \multicolumn{5}{c|}{ Ex ante licensing, N=212 } & \multicolumn{5}{c|}{ Ex post licensing, N=264 } \\
Variable & Mean & Std. Dev. & Min. & Max. & Mean & Std. Dev. & Min. & Max. \\
\hline$\Pi_{a}$ & 1 & 0 & 1 & 1 & 0 & 0 & 0 & 0 \\
$B$ & 0.006 & 0.012 & 0 & 0.088 & 0.008 & 0.012 & 0 & 0.088 \\
\multirow{2}{*}{$P M C$} & 0.579 & 0.423 & 0 & 1 & 0.519 & 0.385 & 0 & 1 \\
$T_{a}$ & 10.448 & 7.244 & 1 & 36 & 7.602 & 6.381 & 0 & 29 \\
$T_{p}$ & 7.368 & 6.956 & 0 & 38 & 7.992 & 7.897 & 1 & 39 \\
$R$ & $94,785.42$ & $38,012.14$ & 52,751 & 152,875 & $84,411.49$ & $36,390.08$ & 52,751 & 169,311 \\
\multirow{2}{*}{$A S M S$} & 0.032 & 0.018 & 0 & 0.099 & 0.031 & 0.024 & 0 & 0.083 \\
DSMS & 0.031 & 0.026 & 0 & 0.144 & 0.026 & 0.028 & 0 & 0.164 \\
ASPS & 586.561 & 584.284 & 0 & 3,292 & 508.617 & 492.631 & 0 & 2,514 \\
\hline \hline
\end{tabular}

This table displays the descriptive statistics of the variables separated by firm pairs that engaged in ex ante and ex post licensing. We use all observations that enter the regression analysis.

Tables 4 and 5 show the descriptive statistics for the overall dataset and for ex ante and ex post licensing separately. Table 4 shows that firms participated on average in 9 (8) ex ante (ex post) licensing contracts. The average semiconductor market share of a firm is $3.2 \%$ and firms hold on average a patent stock of 543 semiconductor patents. Comparing the descriptive statistics between ex ante and ex post licensing (Table 5) shows that firm level characteristics such as market shares and patent stocks are very similar for both groups. Moreover, the means 
of our product market relation variable $(P M C)$ are very similar in both groups. On average blocking $(B)$ is higher for firms which engaged in ex post licensing.

\subsection{Estimation Results}

In this section, we report and discuss our empirical results. The focus is on the specification developed in the previous section but a number of robustness checks are also considered.

Table 6 shows the results from estimating three different specifications. Column (1) shows results from estimating the empirical specification set out in Equation 16. Column (4) contains the corresponding elasticities. Columns (2) and (3) contain results of robustness checks on the specification set out in Column (1).

The results shown in Column (1) are based on 476 observations. These results show that the blocking measure $(B)$ has a significant negative effect on the probability of observing ex ante licensing. Both the coefficient and the elasticity are significant at the $1 \%$ level. Hence, firms are more likely to enter into ex ante (ex post) licensing agreements if their patents block each other to a lower (greater) extent. This finding confirms Hypothesis 1 that lower levels of blocking will induce firms to license ex ante.

The results also show that firms are more likely to enter into ex ante licensing agreements if the degree of product market competition $(P M C)$ between two firms is higher. Both, the coefficient and the elasticity are significant at the $5 \%$ level. This result confirms Hypothesis 2 that higher levels of product market substitution will induce firms to license ex ante. A one standard deviation increase in the degree of product market substitution raises the probability of ex ante licensing by $7.2 \%$.

Finally, the effects of prior experience with ex ante and ex post licensing are as predicted in Hypothesis 3. Therefore, we confirm the hypothesis that greater previous experience of ex ante licensing leads firms to prefer ex ante licensing. Greater experience of ex post licensing leads to further ex post licensing.

Turning to the control variables, we find that larger market size, as measured by industry revenues, lowers firms' propensity to license ex ante. The coefficient and the elasticity on market size are significant at the $1 \%$ level. The negative and significant coefficient for market share $(A S M S)$ shows smaller firm pairs are more likely to license ex ante, whereas larger firm pairs tend to license ex post. The coefficient and elasticity of this measure are significant at the $1 \%$ level. This may indicate that larger firm pairs are less threatened by the same degree of 
blocking and product market substitution. In this case, the result is consistent with the fact that greater competitive pressure leads smaller firms to license ex ante. Greater difference in firm size $(D S M S)$ raises the probability of licensing ex ante. However the coefficient and elasticity of this effect are only weakly significant ( $10 \%$ level) so we refrain from interpreting the result.

Results from a test of the robustness of the timing assumptions made in constructing the blocking measure are reported in Column (2) of Table 6. As noted above we account for the fact that the decision to engage in an ex post licensing contract is made much before the contract is in fact signed. Instead of using a time lag of one period between the decision when firms decide to engage in ex post licensing and signing the contract we now define the blocking variable $(\tilde{B})$ using contemporaneous blocking. This test confirms the robustness of our specification. The magnitude and efficiencies of our parameters are not significantly different from the previous specification. Minor exceptions are the efficiency levels for $(D S M S)$ and $(T I M E)$. The former increased in efficiency from a $10 \%$ to a $5 \%$ level of significance, and the latter decreased in efficiency from a $5 \%$ to a $10 \%$ significance level. Note also that the maximum level of blocking is attained for 0.07 which is still within the range of observed blocking values.

Finally, we allow for potential endogeneity of the blocking measure. Even though blocking is assumed to be exogenous in the theoretical model, $R \& D$ expenditures are endogenously determined. This may indirectly affect our measure of blocking variable, e.g. through a larger patent share. In the empirical application, omitted variables (or unobserved heterogeneity) will be absorbed in the error term which may be correlated with the blocking variable. The blocking variable might be correlated with other factors such as a higher pace of innovation, or higher values of technologies that may cause crowding effects in the technology space.

Since we don't have appropriate variables to account for those factors, they might enter the error term. In order to avoid a potential omitted variables bias, we apply an instrumental variable approach. The challenge is to find an instrument for blocking that is uncorrelated with the above mentioned factors which may enter the error term (instrument exogeneity). Moreover, the instrument should be correlated with the blocking measure (instrument relevance).Lagged blocking may be an appropriate instrument for blocking as it is correlated with blocking but not necessarily correlated with the above mentioned factors. ${ }^{23}$

\footnotetext{
${ }^{23}$ Note that it still is the case that lagged blocking might be correlated with the type of licensing. But the only source of such correlation is the indirect path of lagged blocking being correlated with contemporary blocking, which in turn determines the type of licensing.
} 
Table 6: The probability of observing ex ante licensing

\begin{tabular}{|c|c|c|c|c|}
\hline Dependent Variable: & $\begin{array}{l}(1) \\
\Pi_{a}\end{array}$ & $\begin{array}{l}(2) \\
\Pi_{a}\end{array}$ & $\begin{array}{l}(3) \\
\Pi_{a}\end{array}$ & $\begin{array}{c}\text { Elasticities } \\
\qquad \Pi_{a}\end{array}$ \\
\hline$B$ & $\begin{array}{c}-28.216^{* * *} \\
(6.436)\end{array}$ & & $\begin{array}{c}-63.345^{* * *} \\
(14.548)\end{array}$ & $\begin{array}{c}-0.183^{* * *} \\
(0.042)\end{array}$ \\
\hline$\widetilde{B}$ & & $\begin{array}{c}-28.308^{* * *} \\
(5.594)\end{array}$ & & \\
\hline$P M C$ & $\begin{array}{l}0.378^{* *} \\
(0.164)\end{array}$ & $\begin{array}{l}0.356^{* *} \\
(0.165)\end{array}$ & $\begin{array}{l}0.362^{*} \\
(0.193)\end{array}$ & $\begin{array}{l}0.180^{* *} \\
(0.078)\end{array}$ \\
\hline$T_{a}$ & $\begin{array}{c}0.141^{* * *} \\
(0.021)\end{array}$ & $\begin{array}{c}0.146^{* * *} \\
(0.021)\end{array}$ & $\begin{array}{c}0.100^{* * *} \\
(0.023)\end{array}$ & $\begin{array}{c}1.094^{* * *} \\
(0.174)\end{array}$ \\
\hline$T_{p}$ & $\begin{array}{c}-0.057^{* * *} \\
(0.012)\end{array}$ & $\begin{array}{c}-0.059^{* * *} \\
(0.012)\end{array}$ & $\begin{array}{c}-0.047^{* * *} \\
(0.010)\end{array}$ & $\begin{array}{c}-0.384^{* * *} \\
(0.085)\end{array}$ \\
\hline$R$ & $\begin{array}{c}-0.13 \mathrm{e}-04^{* * *} \\
(4.13 \mathrm{e}-06)\end{array}$ & $\begin{array}{c}-0.13 \mathrm{e}-04^{* * *} \\
(4.14 \mathrm{e}-06)\end{array}$ & $\begin{array}{c}1.21 \mathrm{e}-07 \\
(2.90 \mathrm{e}-06)\end{array}$ & $\begin{array}{c}-1.059^{* * *} \\
(0.333)\end{array}$ \\
\hline$A S M S$ & $\begin{array}{c}-9.945^{* * *} \\
(3.608)\end{array}$ & $\begin{array}{c}-10.257^{* * *} \\
(3.629)\end{array}$ & $\begin{array}{l}-2.907 \\
(3.827)\end{array}$ & $\begin{array}{c}-0.275^{* * *} \\
(0.102)\end{array}$ \\
\hline$D S M S$ & $\begin{array}{l}4.816^{*} \\
(2.705)\end{array}$ & $\begin{array}{l}5.302^{* *} \\
(2.724)\end{array}$ & $\begin{array}{c}5.551 \\
(3.622)\end{array}$ & $\begin{array}{l}0.117^{*} \\
(0.066)\end{array}$ \\
\hline$A S P S$ & $\begin{array}{l}-4.36 \mathrm{e}-04^{*} \\
(2.39 \mathrm{e}-04)\end{array}$ & $\begin{array}{l}-4.33 \mathrm{e}-04^{*} \\
(2.38 \mathrm{e}-04)\end{array}$ & $\begin{array}{c}2.563 \mathrm{e}-04 \\
(3.272 \mathrm{e}-04)\end{array}$ & $\begin{array}{l}-0.207^{*} \\
(0.114)\end{array}$ \\
\hline$T I M E$ & $\begin{array}{l}0.148^{* *} \\
(0.078)\end{array}$ & $\begin{array}{l}0.147^{*} \\
(0.078)\end{array}$ & $\begin{array}{c}-0.603^{* * *} \\
(0.247)\end{array}$ & $\begin{array}{l}0.616^{*} \\
(0.327)\end{array}$ \\
\hline$\sigma$ & & & $\begin{array}{c}0.391^{* *} \\
(0.167) \\
0.009^{* * *} \\
(0.001)\end{array}$ & \\
\hline $\begin{array}{l}\mathrm{N} \\
\text { Log likelihood }\end{array}$ & $\begin{array}{c}476 \\
-287.939\end{array}$ & $\begin{array}{c}476 \\
-284.003\end{array}$ & $\begin{array}{c}379 \\
1,000.719\end{array}$ & 476 \\
\hline
\end{tabular}

This table shows our regression results of equation (16). The main

results and the corresponding elasticities are shown in Columns (1) and (4), respectively.

The results shown in the other columns represent robustness checks. Standard errors are shown in parentheses: ${ }^{* * *}\left({ }^{* *},{ }^{*}\right)$ denotes a $1 \%(5 \%, 10 \%)$ level of significance.

We instrument blocking using its lagged value. Wald test of exogeneity $\rho=0$ :

$\chi^{2}(1)=4.38$, Prob $>\chi^{2}=0.036$. 
We estimate the instrumental variables model by maximum likelihood using the joint distribution of ex ante licensing and blocking. The maximum likelihood procedure uses the information in the density functions for the first and second stages of the model simultaneously and is more efficient than a two stage estimator. The results are reported in column 3 of Table 6 . The magnitudes and efficiencies are consistent with the results from our previous specifications. Consequently, endogeneity of blocking does not significantly affect our empirical results.

We perform several robustness checks for the instrumental variable (IV) estimation. First, we test whether contemporaneous blocking is endogenous. For the maximum likelihood variant with a single endogenous variable, we can apply a Wald test in order to check whether the residuals in the structural equation and the reduced-form equation are correlated using an asymptotic t-test, see Wooldridge (2002). If they are correlated, this implies that the blocking variable is correlated with the error term from the structural equation and therefore must be endogenous. In our case, the Wald test takes on a value of 4.83 which rejects the null hypothesis that blocking is exogenous, see last line in column 5 of Table $6 .{ }^{24}$ We also test the relevance of the instrument, i.e. whether our instrument is correlated with blocking. We regress blocking on lagged blocking. The parameter estimate of 0.644 and the t-statistic of 14.79 confirm that lagged blocking is a strong instrument.

Note that all regressions correctly predict at least $70 \%$ of the observations, which confirms a good fit of our models. Moreover, the empirical results are similar across different specifications in terms of the magnitude and efficiency. The parameter estimates for our main variables, i.e. blocking, product market competition and transaction costs are significant at the $5 \%$ level or better across all specifications. This reconfirms the robustness of the results.

\section{Conclusion}

This paper focuses on licensing contracts, which firms sign in order to counteract a pernicious consequence of patent thickets: the threat that profitable technologies might be held up by rival firms with questionable patents reading on these technologies.

Grindley and Teece (1997) and Lichtenthaler (2007) document that firms in the semiconductor industry use cross-licensing contracts to reduce the threat of hold-up, or in other words, to ensure "freedom to operate". In this paper, we model licensing intended to ensure "freedom

\footnotetext{
${ }^{24}$ The estimate of the correlation between errors $(\rho)$ not being close to 1 or -1 confirms the robustness of the computational algorithm.
} 
to operate". The focus is on the primary effect of such licenses which enable firms to unblock patents that would otherwise be caught in a patent thicket. In particular, we investigate when firms sign such licensing contracts: either ex ante, before $R \& D$ is undertaken, or ex post, after patents have been awarded. Our interest in this question is motivated by the fact that the type of the contracts affects firms' R\&D and patenting incentives.

We model competition for leadership in patent portfolio races and show that firms prefer ex ante licensing whenever competition for leadership in these races is most intense. Whenever blocking is low and/or product market competition between two firms is intense, then incentives to patent are very high. In these cases, ex ante licensing allows firms to lower the cost of competing for patents. Simulation methods are used to demonstrate that either ex ante licensing or ex post licensing may be more profitable, depending on the intensity of the innovation incentives firms face. Furthermore, the robustness of the main theoretical predictions is investigated using simulation. Finally, the paper provides an empirical test of the main theoretical predictions. We are unable to reject the predictions of the theoretical model.

The model we provide in this paper shows that licensing allows firms to overcome some serious problems arising from the patent thicket. Thus, ex ante licensing helps firms to reduce somewhat the very strong incentives to patent that can arise in patent thickets. This paper has focused on the determinants of licensing ex ante and ex post and we have found that ex ante licensing is preferred, as predicted, when competition in the patent thicket is most intense. In future work, we intend to investigate the impact on innovation resulting from ex ante and ex post licensing. In particular, we will investigate whether and, more importantly, by how much ex ante licensing allows firms to lower their levels of patent applications.

Our model is a first attempt to understand the interaction between licensing and patent portfolio races. To derive our predictions, we rely on several simplifying assumptions: we assume that firms are initially symmetrical and that the degree to which patents overlap is exogenous. It might be interesting to relax these assumptions in future research.

\section{References}

American Intellectual Property Law Association, 2004. A.I.P.L.A. response to the October 2003 Federal Trade Commission report: To promote innovation: The proper balance of competition and patent law and policy. Working paper, AIPLA. 
Beath, J., Katsoulacos, Y., Ulph, D., 1989. Strategic R\&D policy. The Economic Journal 99, $74-83$.

Bessen, J., Maskin, E., 2000. Sequential innovation, patents, and imitation. Working Paper 00-01, MIT Deptartment of Economics.

Bloom, N., Schankerman, M., van Reenen, J., 2005. Identifying technology spillovers and product market rivalry. Discussion Paper 3916, CEPR.

Clark, D. J., Konrad, K. A., April 2005. Fragmented property rights, R\&D and market structure. Working Paper 4, University of Tromso, Department of Economics and Management.

Davis, L., February 2008. Licensing strategies of the new intellectual property vendors. California Management Review 50 (2), 6-30.

Federal Trade Commission, October 2003. To promote innovation - the proper balance of competition and patent law and policy. Report, GPO.

Green, J. R., Scotchmer, S., 1995. On the division of profit in sequential innovation. Rand Journal of Economics 25 (1), 20-33.

Grindley, P. C., Teece, D. J., 1997. Managing intellectual capital: Licensing and cross-licensing in semiconductors and electronics. California Management Review 39 (2), 8-41.

Hall, B. H., Jaffe, A. B., Trajtenberg, M., 2005. Market value and patent citations. Rand Journal of Economics 36 (1), 16-38.

Hall, B. H., Ziedonis, R., 2001. The patent paradox revisited: An empirical study of patenting in the u.s. semiconductor industry, 1979-1995. Rand Journal of Economics 32 (1), 101-128.

Jaffe, A. B., 1986. Technological opportunity and spillovers of R\&D: Evidence from firms' patents, profits and market value. American Economic Review 76, 984-1001.

Jaffe, A. B., 2000. The U.S. patent system in transition: Policy innovation and the innovation process. Research Policy 29, 531-557.

Katsoulacos, Y., Ulph, D., 1998. Endogenous spillovers and the performance of research joint ventures. Journal of Industrial Economics 46 (3), 333-357. 
Lanjouw, J. O., Schankerman, M., 2004. Protecting intellectual property rights: Are small firms handicapped? The Journal of Law and Economics 47 (XLVII), 45-74.

Leisch, F., 2002. Sweave: Dynamic generation of statistical reports using literate data analysis. In: Härdle, W., Rönz, B. (Eds.), Compstat 2002 - Proceedings in Computational Statistics. Physica Verlag, Heidelberg, pp. 575-580, http://www.stat.uni-muenchen.de/ Ieisch/Sweave.

Lemley, M., 2001. Rational ignorance at the patent office. Northwestern University Law Review $95(4), 1-39$.

Lerner, J., Strojwas, M., Tirole, J., 2007. The design of patent pools: the determinants of licensing rules. RAND Journal of Economics 38 (3), 610 - 625.

Lerner, J., Tirole, J., 2004. Efficient patent pools. American Economic Review 94 (3), 691 711.

Lichtenthaler, U., 2007. The drivers of technology licensing: An industry comparison. California Management Review 49 (4), 67-89.

Loury, G. C., August 1979. Market structure and innovation. The Quarterly Journal of Economics 93 (3), 395-410.

Nti, K. O., February 1997. Comparative statics of contests and rent-seeking games. International Economic Review 38 (1), 43-59.

Parchomovsky, G., Wagner, R. P., November 2005. Patent portfolios. University of Pennsylvania Law Review 154 (1), 1-77.

Quillen, J. C. D., Webster, O. H., Eichmann, R., 2003. Continuing patent applications and performance of the u.s. patent and trademark office - extended. Federal Circuit Bar Journal $12(1), 35-55$.

R Development Core Team, 2008. R: A Language and Environment for Statistical Computing. R Foundation for Statistical Computing, Vienna, Austria, ISBN 3-900051-07-0 http://www.R-project.org. 
Reinganum, J. F., 1989. The timing of innovation: Research, development and diffusion. In: Schmalensee, R., Willig, R. D. (Eds.), Handbook of Industrial Organization. Vol. 1. Elsevier Science, Amsterdam, Netherlands, pp. 850-908.

Schankerman, M., Noel, M., 2006. Strategic patenting and software innovation. Discusion Paper 5701, CEPR.

Scotchmer, S., 2005. Innovation and Incentives. MIT Press, Cambridge, Mass.

Shapiro, C., 2001. Navigating the patent thicket: Cross licenses, patent pools, and standardsetting. In: Jaffe, A. B., Lerner, J., Stern, S. (Eds.), Innovation Policy and the Economy. Vol. 1. MIT Press, Cambridge, Mass., pp. 119-150.

Shapiro, C., 2003. Antitrust limits to patent settlements. RAND Journal of Economics 34 (2), $391-411$.

Siebert, R., von Graevenitz, G., Jan. 2008. Does licensing resolve hold up in the patent thicket? Discussion Papers in Business Administration 2104, University of Munich, Munich School of Management.

Somaya, D., 2003. Strategic determinants of decisions not to settle patent litigation. Strategic Management Journal 24 (1), 17-38.

von Graevenitz, G., Wagner, S., Harhoff, D., 2008. Incidence and growth of patent thickets the impact of technological opportunities and complexity. Discussion Paper 6900, CEPR.

Wooldridge, J. M., 2002. Econometric analysis of cross section and panel data. MIT Press, Cambridge, Mass.

Ziedonis, R. H., 2004. Don't fence me in: Fragmented markets for technology and the patent acquisition strategies of firms. Management Science 50 (6), 804-820. 


\section{Appendix A - Proofs}

\section{A.1 The effect of blocking on firms' ex post investments}

Here we investigate the effects of increased blocking on firms' equilibrium $R \& D$ investment levels under ex post licensing. First we set out the general expressions. Then we set out results for the case of linear demand.

General expressions Here we consider the sign of the following derivative, as set out at ( (13)) above:

$$
\frac{\partial \hat{h}_{p}}{\partial B}=-\frac{\partial R_{p}}{\partial B}\left(\frac{\partial R_{p}}{\partial \hat{h}_{p}}\right)^{-1}
$$

First we derive the sign of the denominator. We can show that the denominator must be negative if the equilibrium characterized by Equation (5) is stable. The following expression shows that the sign of the denominator depends on the difference of two terms:

$$
\frac{\partial R_{p}}{\partial \hat{h}_{p}}=\frac{1}{\left(N \hat{h}_{p}+r\right)^{2}}[(N-1) \underbrace{\left[\frac{\triangle v}{r}-\gamma^{\prime}\left(\hat{h}_{p}\right)\right]}_{\xi}-\gamma^{\prime \prime}\left(\hat{h}_{p}\right)\left(N \hat{h}_{p}+r\right)]
$$

Local stability of equilibrium requires that:

$$
\left|\frac{\partial^{2} V_{p}}{\partial h_{p}^{2}}\right|>\left|\frac{\partial^{2} V_{p}}{\partial h_{p} \partial h_{p}^{j}}\right| \Leftrightarrow\left|-\gamma^{\prime \prime}\left(\hat{h}_{p}\right)\left(N \hat{h}_{p}+r\right)\right|>\left|\left[\frac{\triangle v}{r}-\gamma^{\prime}\left(\hat{h}_{p}\right)\right]\right| .
$$

Note that $h_{p}^{j}$ is the hazard rate of one rival firm. Local stability of equilibrium implies that the denominator set out in expression (A2) is negative if there are just two firms.

Now consider the numerator of the expression in equation (A1). To sign the numerator we sign the effect of greater blocking strength on the difference between the values of winning and losing the patent portfolio race $(\Delta v)$ and on the expected value of winning by itself $\left(v_{l}\right)$. Equation (6) above shows these two terms determine the strength of the competitive threat and the profit incentive, respectively.

Here we can show that:

$$
\frac{\partial R_{p}}{\partial B}=\frac{1}{2 r\left(2 \hat{h}_{p}+r\right)}\left[\frac{\partial \pi}{\partial \bar{q}} \frac{\bar{\partial} \bar{q}}{\partial B}-\frac{\partial \pi}{\partial Q} \frac{\partial \bar{Q}}{\partial B}\right]
$$


This shows that when two firms are producers of substitute products $\left(\frac{\partial \pi}{\partial Q}<0\right)$, the derivative $\frac{\partial R_{p}}{\partial B}$ is negative. If firms produce complementary products $\left(\frac{\partial \pi}{\partial Q}>0\right)$ we cannot $\operatorname{sign} \frac{\partial R_{p}}{\partial B}$.

Linear demand Now consider the proofs for Corollaries ?? and ??.

The case of two firms: $\frac{\partial R_{p}}{\partial B}$ may be rewritten as:

$$
\begin{aligned}
\frac{1}{2 r\left(2 \hat{h}_{p}+r\right)}\left[\frac{\partial \pi}{\partial \bar{q}(B)}-\right. & \left.\frac{\partial \pi}{\partial Q}\right] \frac{\partial \bar{q}(B)}{\partial B} \\
& =-\frac{1}{r\left(2 \hat{h}_{p}+r\right)} \frac{(1+2 \sigma)[(a-\bar{c})(2-\sigma)+(\bar{c}-\tilde{c})]}{(2+\sigma(n-1))^{2}(2-\sigma)^{2}} \frac{\partial \tilde{c}}{\partial \bar{q}} \frac{\partial \bar{q}(B)}{\partial B}
\end{aligned}
$$

This expression is negative where $\sigma>0$, compare Proposition 3. It will be positive if $1+2 \sigma<0$, i.e. when $\sigma<-\frac{1}{2}$. Thus two firms facing linear demand and producing very complementary products would gravitate towards ex post licensing if the blocking strength of their patent portfolios rises.

\section{Simulations}

In this section we set out the linear demand case in detail. First we present the model and then we provide output from a simulation of the model using R. ${ }^{25}$

\section{A.2 An example using linear demand}

Assume that the inverse demand function is linear:

$$
\left.\left.p_{i}=a-x_{i}-\sigma \sum_{j \neq i}^{n} x_{j} \quad \text { where } \sigma \in\right]-\frac{2}{n-1}, 1\right]
$$

There are $1 \leq N \leq n$ efficient firms with $\operatorname{costs} \tilde{c}(B)$ and $n-N$ inefficient firms with costs $\bar{c}$ in the market. We denote all variables related to the efficient firms with and all those related to the inefficient firms with ${ }^{-}$. Assuming that the firms compete in quantities the first order conditions for profit maximization imply that:

$$
(\bar{p}-\bar{c})=\bar{x} \quad \text { and } \quad(\tilde{p}-\tilde{c})=\tilde{x}
$$

\footnotetext{
${ }^{25}$ We make use of the Sweave (Leisch, 2002) package within R to show ho our simulations work. This code can be used to check the results we derive.
} 
Combining the first order conditions with the inverse demand function we can show that:

$$
\begin{aligned}
& \tilde{p}=a-(\tilde{p}-\tilde{c})(1+\sigma(N-1))-(\bar{p}-\bar{c}) \sigma(n-N) \\
& \bar{p}=a-(\tilde{p}-\tilde{c}) \sigma N-(\bar{p}-\bar{c})(1+\sigma(n-N-1))
\end{aligned}
$$

which implies that:

$$
\tilde{p}-\bar{p}=-(\bar{c}-\tilde{c}) \frac{(1-\sigma)}{(2-\sigma)}, \quad \tilde{p}=\frac{A+(\bar{c}-\tilde{c})\left(\frac{1+\sigma(n-N)}{2-\sigma}\right)}{(2+\sigma(n-1))}+\tilde{c}, \quad \bar{p}=\frac{A-(\bar{c}-\tilde{c}) \frac{\sigma N}{(2-\sigma)}}{(2+\sigma(n-1))}+\bar{c}
$$

where we define $A=a-\bar{c}$. Then firms' profits in equilibrium are:

$$
\bar{\pi}=\left(\frac{A-(\bar{c}-\tilde{c}) \frac{\sigma N}{(2-\sigma)}}{2+\sigma(n-1)}\right)^{2} \quad \tilde{\pi}=\left(\frac{A+(\bar{c}-\tilde{c})\left(\frac{1+\sigma(n-N)}{2-\sigma}\right)}{(2+\sigma(n-1))}\right)^{2}
$$

Below we will often need to take the derivative of the difference of these profits:

$$
\frac{\partial(\tilde{\pi}-\bar{\pi})}{\partial \tilde{c}}=\frac{(1+\sigma n)}{(2+\sigma(n-1))^{2}(2-\sigma)^{2}}(2 A(2-\sigma)+(\bar{c}-\tilde{c})(1+\sigma(n-2 N)))
$$

\section{A.3 Graphs}

First we define profits, where pie and pin are the profits of the efficient and the inefficient firm as at (A11). pis are profits if firms license ex ante. Finally, pi0 are initial profits.

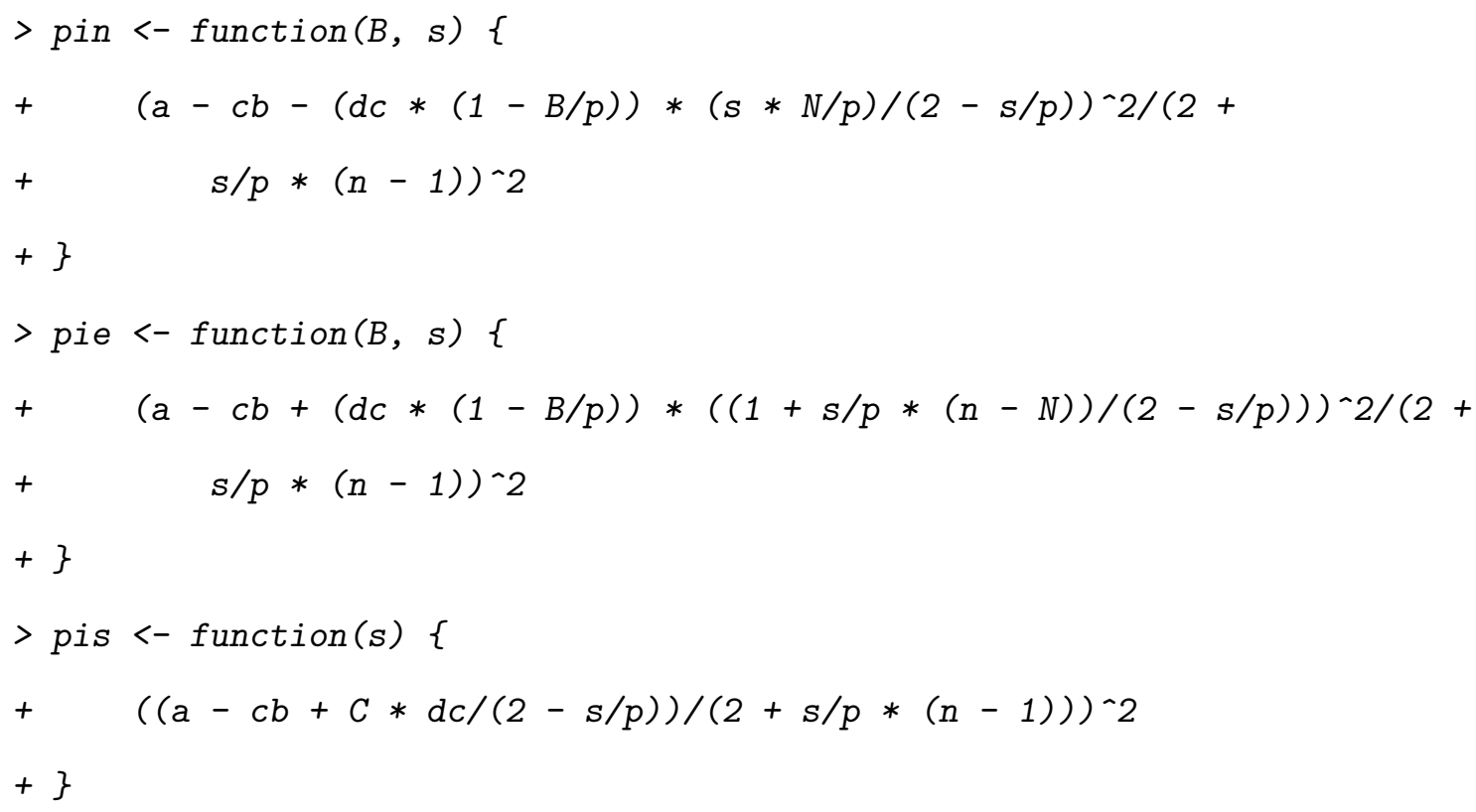




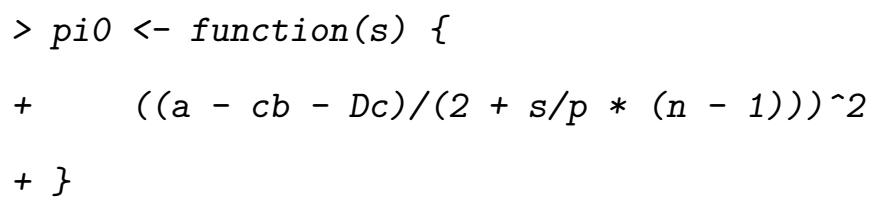

Next we define the value functions as at (7) and (12) as well as their squared derivatives:

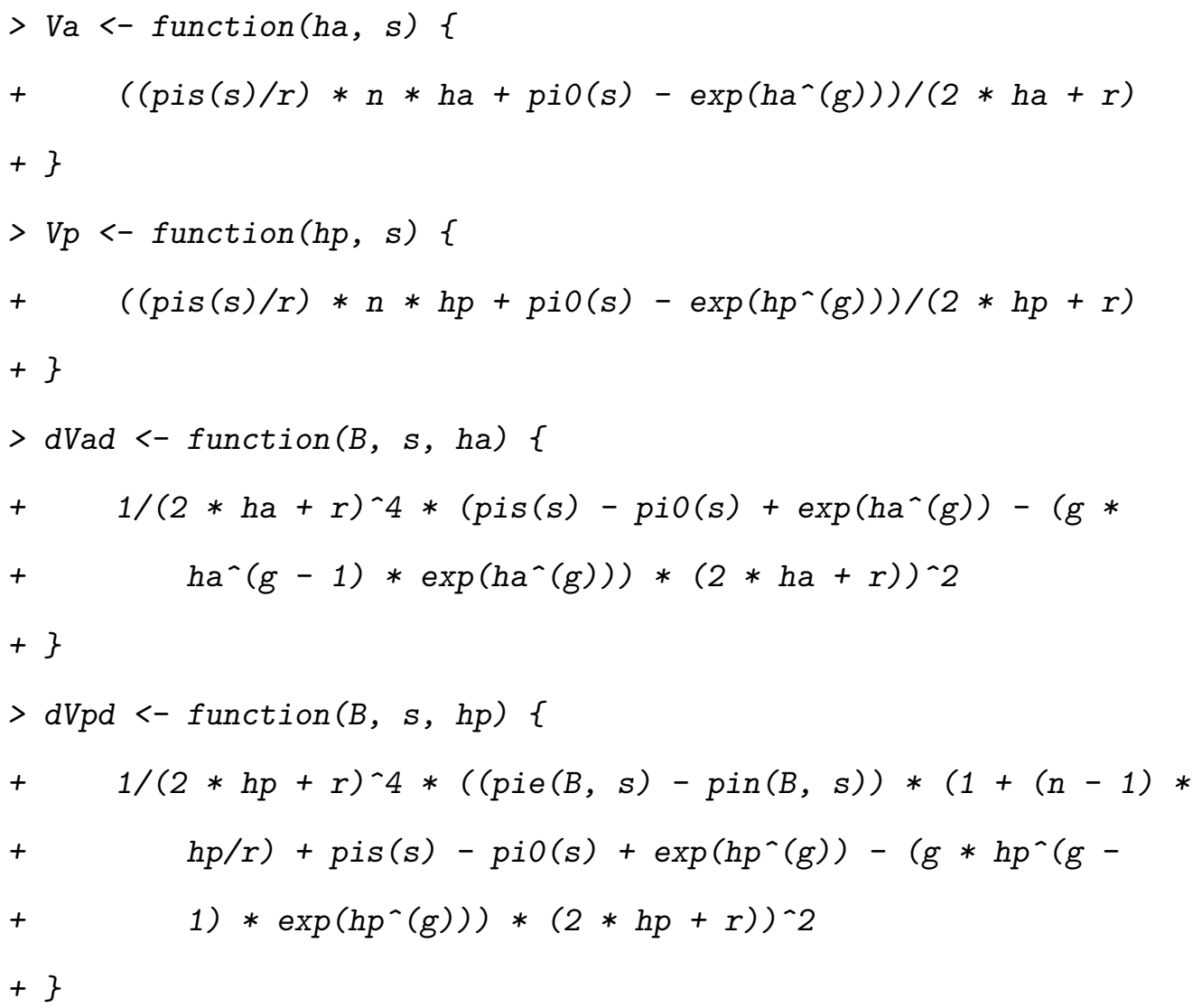

Now set the values of various variables:

$$
\begin{aligned}
& >p<-100 \\
& >a<-100 \\
& >r<-0.04 \\
& >g<-1 \\
& >c b<-80 \\
& >d c<-4 \\
& >D c<-4 \\
& >N<-1 \\
& >n<-2 \\
& >C<-2
\end{aligned}
$$


Note that $\mathrm{p}$ is a scaling factor for blocking B. As set here we let B increase in steps of 0.01 . All graphs are produced with the following settings: $a=100 ; r=0.04 ; n=2$ and we assume that the $\mathrm{R} \& \mathrm{D}$ cost function is $\gamma(h)=e^{h}$. Here we assume that the inefficient firm has costs of 80 and the efficient firm reduces its costs by 4 . In the graphs below we always have one firm which is more efficient than the other. Only the efficient firm reduces its costs here. Note that $d c=(\bar{c}-\tilde{c})$.

Then we find optimal R\&D investments, determine the values of ex ante and ex post licensing and plot the results:

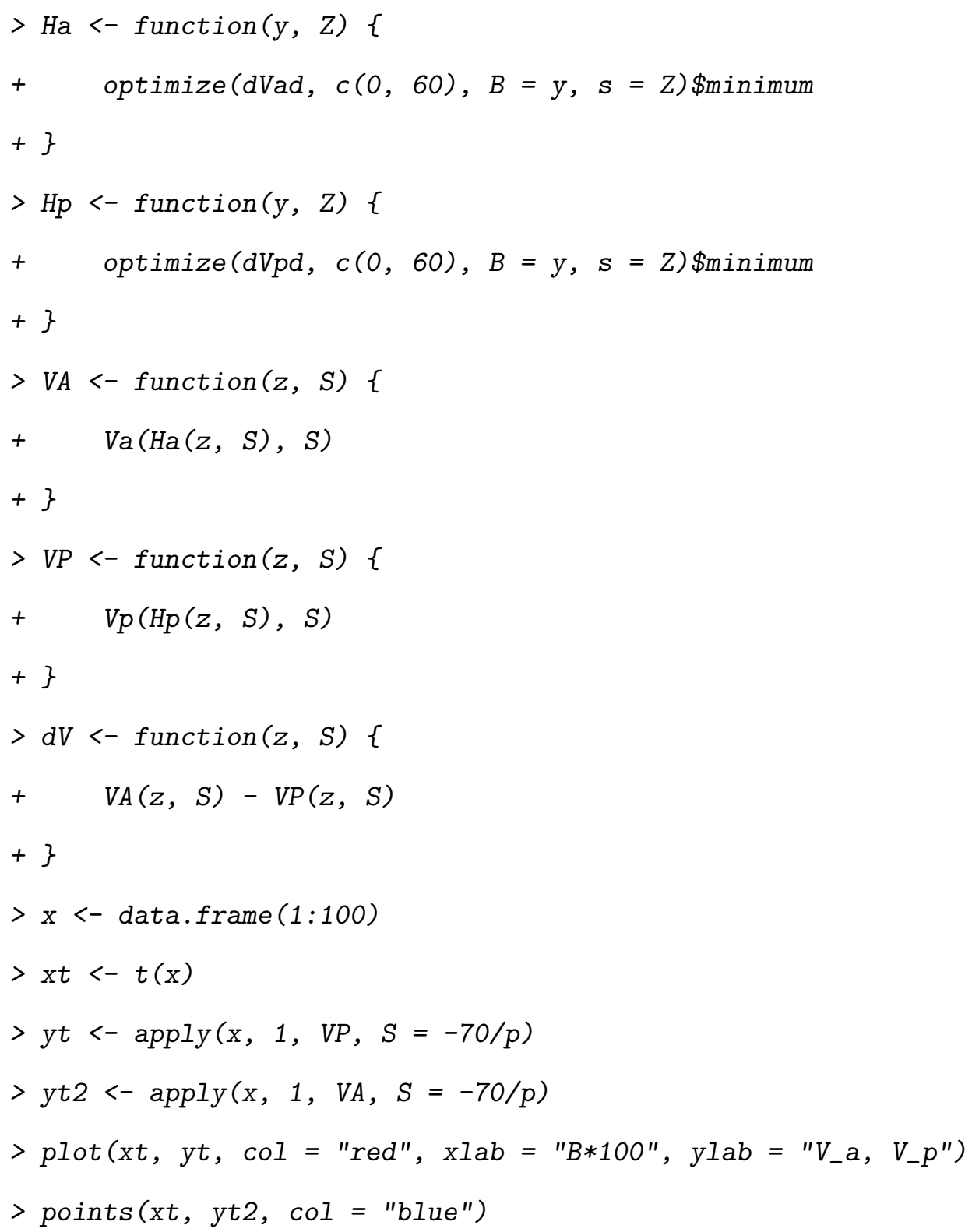




\section{A.4 Examples of Licensing Agreements}

\section{A.4.1 Ex ante licensing}

03/04/1991

National Semiconductor Corp. and Fujitsu, Ltd. have signed a ten-year cross-licensing agreement which covers all of their current semiconductor patents. Also covered are all products developed by either company for the duration of the agreement. The two companies hope to increase their strength in the semiconductor arena and decrease the chance of infringing on each other's patent rights as a result of the agreement.

06/12/1997

Texas Instruments and NEC Corp entered into a ten-year cross-licensing agreement to patent semiconductors. Under the terms of the agreement, the two companies were to have use of each others patents involved in manufacturing semiconductors.

\section{A.4.2 Ex post licensing}

$01 / 11 / 1995$

Advanced Micro Devices and Intel Corp signed a licensing agreement in which Intel gave Advanced Micro Devices a perpetual license to use the microcode of the 386 and 486 microprocessors. In addition, the two firms were also to negotiate a patent cross-licensing agreement to succeed a licensing agreement which was to run out at the end of 1995 . Under the terms of the agreement, Advanced Micro agreed not to copy the microcode from any other Intel microprocessors such as the Pentium, the P6, or the 80486 in-circuit emulation microcode. Advanced Micro Devices was allowed to use the licensed microcode for up to $20 \%$ of its production of AM486 microprocessors.

$01 / 05 / 1995$

Motorola Inc and International Rectifier Inc granted each other a cross-license to their patents held by both companies in the technologies of power MOSFETs, IGBTs, power ICs, rectifiers, thyristors, and diodes. Specific and financial details were not disclosed. 